\title{
Screw thermal characteristics analysis and error prediction considering the two-dimensional heat transfer structure
}

\author{
Yu Chen \\ Jihong Chen \\ guangda xu ( $\nabla$ xu_guangda@hust.edu.cn) \\ Huazhong University of Science and Technology
}

\section{Research Article}

Keywords: Thermal error, Thermal characteristics, Particle swarm optimization (PSO), Screw-nut feed system, Parameter identification

Posted Date: February 11th, 2021

DOl: https://doi.org/10.21203/rs.3.rs-158124/v1

License: (c) (i) This work is licensed under a Creative Commons Attribution 4.0 International License. Read Full License 


\title{
Screw thermal characteristics analysis and error prediction considering the two-dimensional heat transfer structure
}

\author{
Yu Chen, Jihong Chen and Guangda Xu* \\ National Numerical Control System Engineering Research Center, \\ Huazhong University of Science and Technology, Wuhan 430074, China \\ E-mail address of the corresponding author: xu_guangda@hust.edu.cn
}

\begin{abstract}
Thermal error is a common problem in machine tool processing. It is usually proposed to take the screw as one-dimensional rod heat transfer system to solve the thermal error of screw by establishing thermal characteristic equation. This method regards the temperature on the nut as the temperature of the screw contact surface without considering the heat transfer distance between screw and the mounting point on the nut. To solve this problem, this paper takes the screw-nut feed system as a twodimensional heat transfer structure considering both screw and nut. In addition, to solve the low convergence speed and easy fall into local optimum problem in optimal parameter identification. The improved particle swarm optimization algorithm (IPSOA) is proposed to identify the boundary parameters of thermal characteristics equations. Finally, the temperature and thermal error of the screw-nut feed system is calculated by the identified results. Experiments under different working condition show that the maximum prediction residual error of the two-dimensional method (TDM) is less than $7.2 \mathrm{um}$ and the simulating prediction accuracy can reach $86.2 \%$. Besides, compared with one-dimensional model (ODM), TDM has a higher predict accuracy which verifies the effectiveness of the proposed method.
\end{abstract}

\section{Keywords}

Thermal error Thermal characteristics Particle swarm optimization (PSO)

Screw-nut feed system Parameter identification

\section{Introduction}


The thermal error caused by heating lead to relative position of the moving shaft, which affect the machining quality and precision of parts. According to statistics, the thermal error accounts for $40-70 \%$ of the total error[1], and the proportion is larger in precision machining process. Therefore, reducing the influence of thermal error is of great significance to improve the machining quality of machine tools.

The main methods to solve thermal error are error active suppression method and error compensation method[2]. Active error suppression methods include thermal friendly structure design[3], cooling device[4], constant temperature workshop[5] etc. Considering the machine tool structure, additional use costs and application effect, the error compensation method is more widely used at present. Thermal error compensation method is a compensation method based on embedded software of CNC system. The compensation algorithm of modeling can be divided into two categories which are models based on data driven and physics method. The data driven model is mainly based on the temperature sensitive point. For this method, the temperature sensitive point must be determined and establish the mathematical model between the temperature sensitive point and the thermal error. The way to find temperature sensitive point include cluster analysis[6], Lasso[7], fuzzy c-means clustering[8], correlation analysis [9], Gaussian integration method[10], etc. The related modeling methods include Elman neural network[11], adaptive support vector machine[12], dynamic model[13], etc. The data-driven method has achieved certain results, but it takes a certain time to find the temperature sensitive point. Therefore, some researchers try to establish the physical model of thermal error by analyzing the thermal characteristics of machine tools.

The physical modeling method establishes the heat balance equation of the feed screw from the perspective of heat transfer. Li Tiejun proposed the thermal balance equation of the screw and identified the relevant physical parameters by using Monte Carlo, after that the thermal error was calculated and proved the FEM method can improve the results both in time and accuracy[14]. JacekZapłata calculated the heat output of nuts and bearings at different speed, then found the mapping relation between heat sources and speed. At last, the change rules of thermal characteristic parameters at 
different speed was obtained[15]. Liu Kuo proposed the heat value and heat conduction coefficient of the nut through optimization theory, then input these parameters into DBN model to evaluate the reliability of thermal error parameters[16]. Yang Jianguo mounted a temperature sensor on the screw nut to obtain the thermal error curve of the whole screw, after that he established the thermal error model of the micro unit on the screw[8]. Naeem S. Mian use FEA to simulate the thermal deformation of machine tools in different seasons, which reduces the collecting thermal error data time used for environmental temperature modeling[17].

The above thermal error modeling and compensation method take into account the thermal mechanism characteristics of machine tools and have achieved certain results, but there are also some shortcomings (1) Simplifying the screw heating model into a one-dimensional bar system is not enough. (2) The parameter identification method of Monte Carlo is a random simulation method and the convergence speed is slow. In view of the above problems, this paper simplifies the screw heating model into a twodimensional structure by considering the conduction distance between the temperature measure point on nut and screw. Besides, it can improve the convergence speed and avoid falling into the local optimal solution by using the IPSOA to solve the heat conduction equations.

The second chapter introduces the calculation method of screw thermal characteristics and the principle of PSO. In the third chapter, the thermal error modeling method of screw-nut based on thermal analysis and IPSOA is proposed. Firstly, the thermal characteristics of two-dimensional screw-nut is comprehensive analyzed, and then the thermal balance equation of screw-nut feed system is established by using the second law of thermodynamics. After that, the objective function between measured temperatures and calculated temperatures is obtained, then the thermal characteristic parameters are identified by IPSOA. Finally, the thermal error model of screw-nut is established according to the identified parameters. In the fourth chapter, experiments of different working condition are conducted and the TDM predict result is compared with ODM.

\section{Prelimilary}




\subsection{Thermal characteristic analysis of screw-nut feed system}

In the processing of high-speed CNC machine tool, the heat source of screw feed system includes internal and external. The internal heat source is divided into two parts, one is the heat generated by the friction of the screw nut and the other is the heat generated by the friction between the bearings at both ends[18]. The external heat source mainly refers to the heat conduction of motor output shaft and environmental radiation heat. If the plastic coupling with low conductivity is used in the screw feed system, the influence of motor heating on the thermal deformation of the screw can be ignored. Therefore, the friction heating of the screw nut pair and the bearings at both ends are the two main heat sources in the operation of the screw. In addition, the influence of ambient temperature should be considered. As shown in Fig. 1, The uneven temperature field will be formed due to the unequal heat and heat dissipation on the screw and then thermal error will be generated, which lead to the decrease of machining accuracy[19].

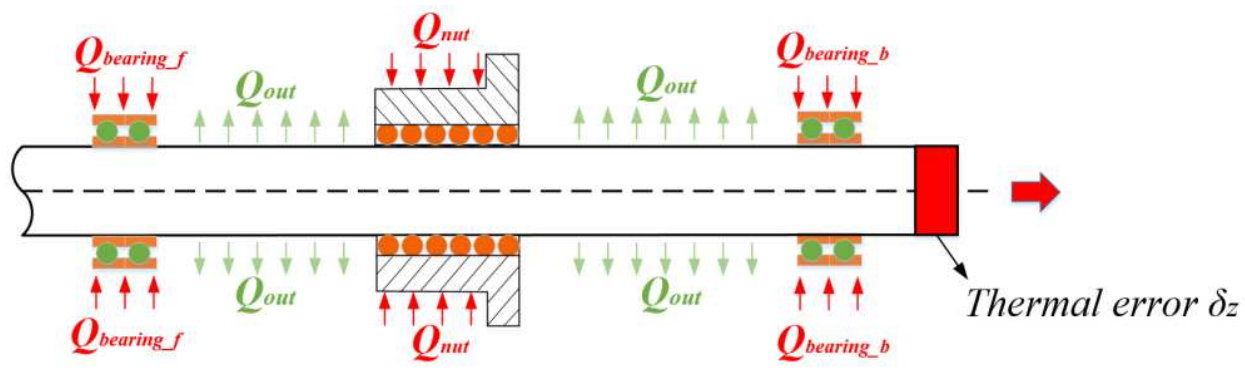

Fig.1 Causes of thermal deformation relating to feed screw

\subsubsection{Heat generation}

1) Heat generation of bearings can be expressed as[20]

$$
Q_{\text {bearing }}=1.047 \times 10^{-4} n M
$$

Where $n$ is feed screw speed and $M$ is total friction torque of bearing. The friction moment $M$ consists of two parts

$$
M=M_{1}+M_{v}
$$

Where $M_{l}$ is friction torque caused by load and $M_{v}$ is friction torque caused by viscosity of lubricant.

The heat generation calculation of ball screw nut pair as Eq. (2.3) and it can 
conclude that the heat generation of nut is proportional to speed. The total friction torque $M_{n u t}$ of ball screw nut pair is composed of driving torque $M_{a}$ of screw and resistance moment $M_{p}$ of ball screw.

$$
\begin{aligned}
& Q_{n u t}=0.12 \pi n_{n u t} M_{n u t} \\
& M_{n u t}=0.94 M_{a}+M_{p}
\end{aligned}
$$

The driving torque $M_{a}$ and resistance moment $M_{p}$ is calculated as Eq.(2.5) and Eq.(2.6).

$$
\begin{gathered}
M_{D}=\frac{F_{a} P_{h}}{2 \pi \eta} \\
M p=\frac{F_{a} P_{h}}{2 \pi \eta}\left(1-\eta^{2}\right)
\end{gathered}
$$

Where $F_{a}$ is axial load, $P_{h}$ is lead of the screw and $\eta$ is transfer efficiency.

\subsubsection{Heat dissipation}

1) Natural convection heat dissipation

$$
Q_{\text {natural }}=h \times S \times\left(T_{\text {screw }}-T_{\text {envir }}\right)
$$

Where $h$ is convective heat dissipation coefficient of feed screw, $S$ is contact area between the feed screw and the outside world, $T_{\text {screw }}$ is feed screw temperature, $T_{\text {envir }}$ is ambient temperature, the meaning of the relevant parameters is as follows[19].

$$
\begin{gathered}
h=\frac{N_{u} \square \lambda_{f}}{L} \\
N_{u}=\left(C \square G_{r} \square \mathrm{P}_{r}\right)^{\frac{1}{3}} \\
G_{r}=\frac{g \square \beta \square L^{3} \square \Delta T}{v^{2}}
\end{gathered}
$$

2) Forced convection heat dissipation

$$
\begin{gathered}
N_{u}=0.133 R_{e}^{\frac{2}{3}} P_{r}^{\frac{1}{4}} \\
R_{e}=\frac{\pi n_{n u t} d^{2}}{60 v}
\end{gathered}
$$

From Eq. (2.11-2.12) it can draw a conclusion that the heat generation of nut is 
exponential to nut speed.

3) Calculation of heat conduction

$$
Q_{\text {con }}=\lambda \sqcap A \sqcap \Delta T
$$

Where $\lambda$ is heat conduction coefficient of feed screw, $S$ is equivalent conduction area of feed screw, $\Delta T$ is heat conduction temperature difference of feed screw.

\subsection{The principle of PSO algorithm}

PSO is a classical swarm intelligence optimization algorithm to find the optimal value, which is inspired by birds' foraging behavior[21][22]. It has been widely used in function optimization[23], neural network training[24], fuzzy system control[25] and other genetic algorithms[26]. The optimization process of PSO is to generate a random population within the range of constraints. Each particle in the population has its own position and speed, each particle will find the best position of the individual $X_{i, p b e s t}^{t}$ and the best position of the population $X_{i, g b e s t}^{t}$ by comparing the value of the particle into the objective function. In the next iteration, the velocity and position of the current particle will be updated with the $V_{i}^{t}, X_{i, p b e s t}^{t}, X_{i, g b e s t}^{t}$ of the previous iteration of the particle, and the optimal value within the range of constraints will be finally found. The update particle position and velocity are as Eq.(2.14-2.15)

$$
\begin{gathered}
V_{i}^{t+1}=w \cdot V_{i}^{t}+c_{1} r_{1}\left(X_{i, p b e s t}^{t}-X_{i}^{t}\right)+c_{2} r_{2}\left(X_{i, g b e s t}^{t}-X_{i}^{t}\right) \\
X_{i}^{t+1}=X_{i}^{t}+V_{i}^{t+1}
\end{gathered}
$$

Where $V_{i}^{t+1}, X_{i}^{t+1}$ denote the velocity and position of the $i$-th particle in the $t+1$ iteration respectively. $X_{i, g b e s t}^{t}$ is the best historical position of the $i$-th particle in the $t$ th iteration. $W$ is the inertia weight of the particle, $c_{1}$ and $c_{2}$ are the learning factors, $r_{1}$ and $r_{2}$ are the random numbers between 0 and 1.

The inertia weight $w$ is usually expressed by Eq.(2.16)

$$
w=w_{\max }-\left(w_{\max }-w_{\min }\right) \cdot \frac{C_{i t e r}}{M_{i t e r}}
$$

Where $C_{i t e r}$, Miter represent the current number of iterations and the maximum 
number of iterations respectively. $w_{\max }, w_{\min }$ represent the maximum and minimum values of weight change respectively.

\section{Modeling method}

The overall framework of screw thermal error modeling method based on IPSOA considering thermal characteristics is shown in Fig.2. It mainly includes the establishment of two-dimensional heat balance equation, boundary condition identification based on IPSOA, thermal error calculation.

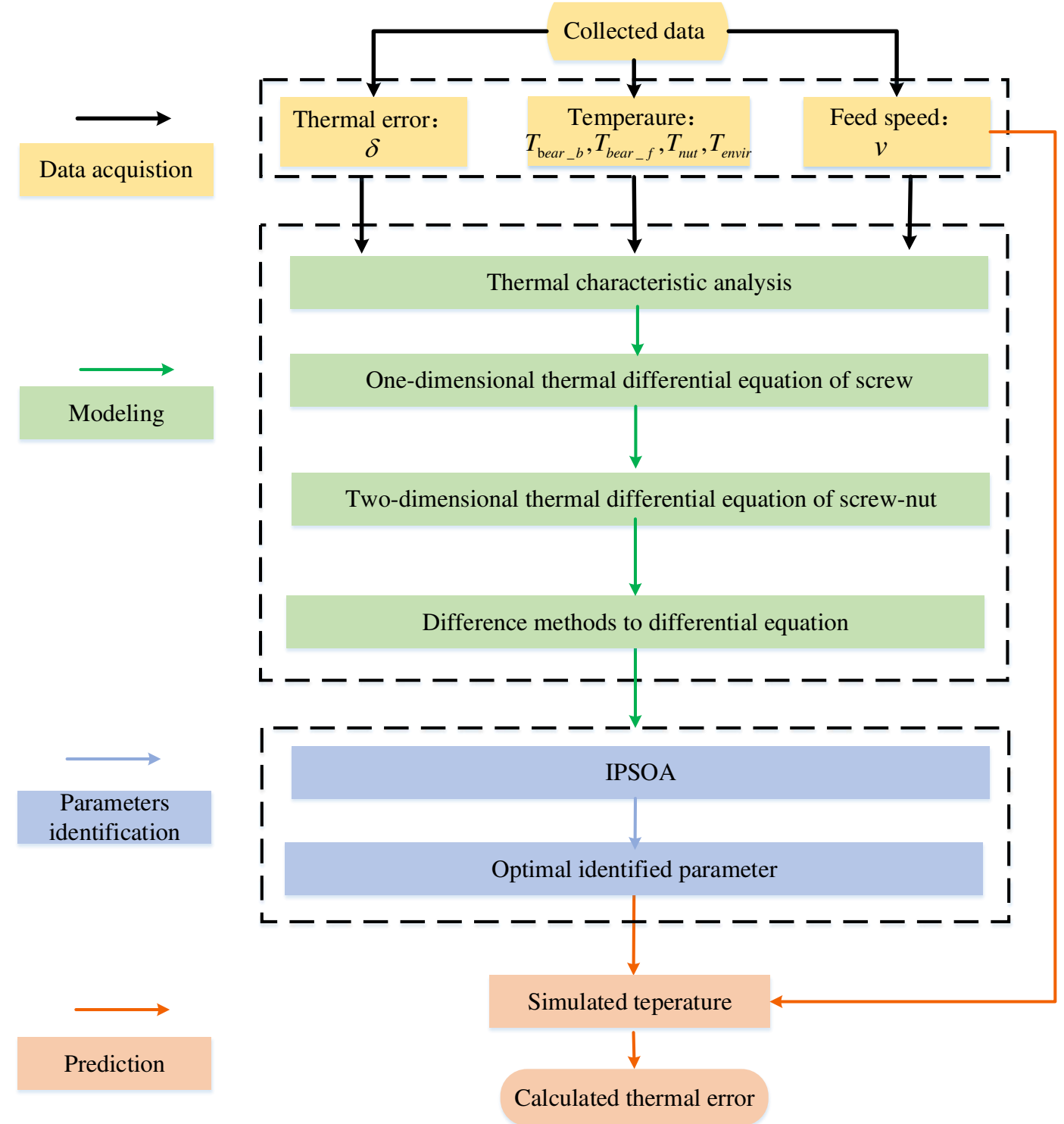

Fig.2 Process of thermal error modeling method

\subsection{One-dimensional thermal differential equation of screw}

It is assumed that the axial material of screw is uniform then the screw can divide into several micro units along its axial direction. 


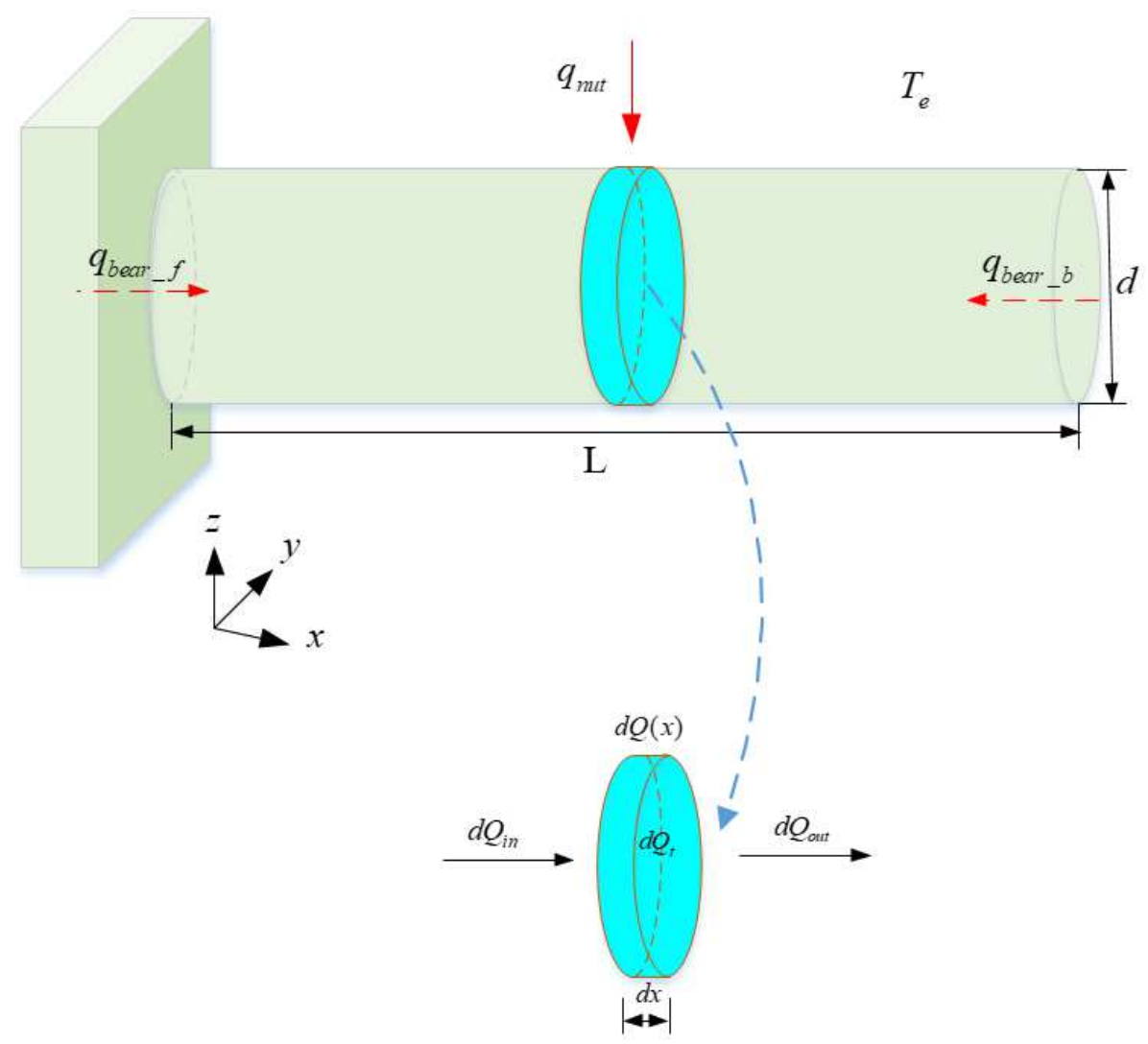

Fig.3 Thermal analysis of screw micro unit

According to the conservation of energy, Eq.(3.1) can be obtained.

$$
d Q_{t}=d Q_{\text {in }}-d Q_{\text {out }}+\mathrm{d} Q(x)
$$

Where, $d Q_{t}$ is the total heat energy of micro unit, $d Q_{i n}$ is the absorbing heat energy of micro unit, $d Q_{\text {out }}$ is the releasing heat energy of micro unit, $d Q(x)$ is the heat energy come from nut or bearings.

Furthermore, the micro heat energy can be replaced by the heat flux density, namely $d Q_{t}, d Q_{\text {in }}, d Q_{\text {out }}, d Q(x)$ is equal to $q_{t}, q_{\text {in }}, q_{\text {out }}, q(x)$. It can be seen from Eq. (2.3) and Eq. (2.12) that the calculation method of $q(x)$ is also closely related to the running speed. Therefore, the expression of $q(x)$ can be updated to $q(x, v)$.

$$
q_{t} A_{c} d_{x}=q_{\text {in }} A_{c}-q_{\text {out }} A_{c}+q(x, v) A_{s}
$$

Where $A_{c}$ is cross section area of micro unit, $A_{s}$ is the surface area of micro unit. When the differential unit is in different positions, the calculation methods of $q(x, v)$ are calculated as follows: 


$$
q(x, v)=\left\{\begin{array}{cc}
q_{n u t}(x, v) & \text { nut } \\
q_{\text {bearing_f }}(x, v) & \text { front bearing } \\
q_{\text {bearing_b }}(x, v) & \text { back bearing } \\
-h(x, v)\left[T(x, t)-T_{e}\right] & \text { other position on screw }
\end{array}\right.
$$

Where $h$ is the convective heat exchange coefficient between the structure and the surrounding air, $T_{e}$ is the ambient temperature. Since the forced heat dissipation coefficient and natural heat dissipation coefficient are greatly affected by the change of speed, $q_{n u t}(x, v)$ and $h(x, v)$ should calculated from Eq.(3.4-3.5) based on the identified parameters according to Eq.(2.3) and Eq.(2.12). Where $v_{b}$ is the base identified speed and $v_{r}$ is the real speed.

$$
\begin{aligned}
& q_{n u t}(x, v)=\frac{v_{r}}{v_{b}} q_{n u t}^{b}(x, v) \\
& h(x, v)=\left(\frac{v_{r}}{v_{b}}\right)^{\frac{2}{3}} h_{b}(x, v)
\end{aligned}
$$

The rate of heat energy entering the control volume is equal to heat transfer rate of the cross-section at x. According to Fourier's Law

$$
q_{\text {in }}(x, t)=-\lambda_{x} \frac{\delta T(x, t)}{\delta x}
$$

Where, $\lambda_{x}$ is the thermal conductivity of the screw, $A_{c}$ is the cross-sectional area of the structural member; $T(x, t)$ is the temperature of the cross-section at $\mathrm{x}$ of the structural member at time t. The heat transfer rate at $x+d x$ as the heat dissipation rate of the round heat exchange surfaces can be expressed as

$$
q_{\text {out }}(x, t)=q_{x}+\frac{d q_{x}}{d x} d x
$$

Similarly, it can be concluded that

$$
q_{\text {out }}(x, t)=-\lambda_{x} \frac{\partial T(x, t)}{\partial x}-\lambda_{x} \frac{\partial^{2} T(x, t)}{\partial x^{2}} d x
$$

The energy storage term in the microelement can be expressed as

$$
q_{t}(x, t)=\rho c \frac{\partial T(x, t)}{\partial t} d x
$$

Where $\rho$ is the material density of the structural member and $c$ is the specific heat capacity of the structural member material. By substituting the above formula into 
Eq.(3.2), the expression of dynamic heat balance of one-dimensional bar unit under the action of heat source is obtained as Eq.(3.10). $A_{c}$ is cross section area of micro unit, $A_{s}$ is the surface area of micro unit.

$$
\lambda_{x} A_{c} \frac{\partial^{2} T(x, t)}{\partial x^{2}}=\rho c \frac{\partial T(x, t)}{\partial t} A_{c}+q(x, v) A_{s}
$$

Where $A_{c}=\pi d^{2} / 4, A_{s}=\pi d \cdot d x$.

\subsection{Two-dimensional thermal differential equation of screw-nut}

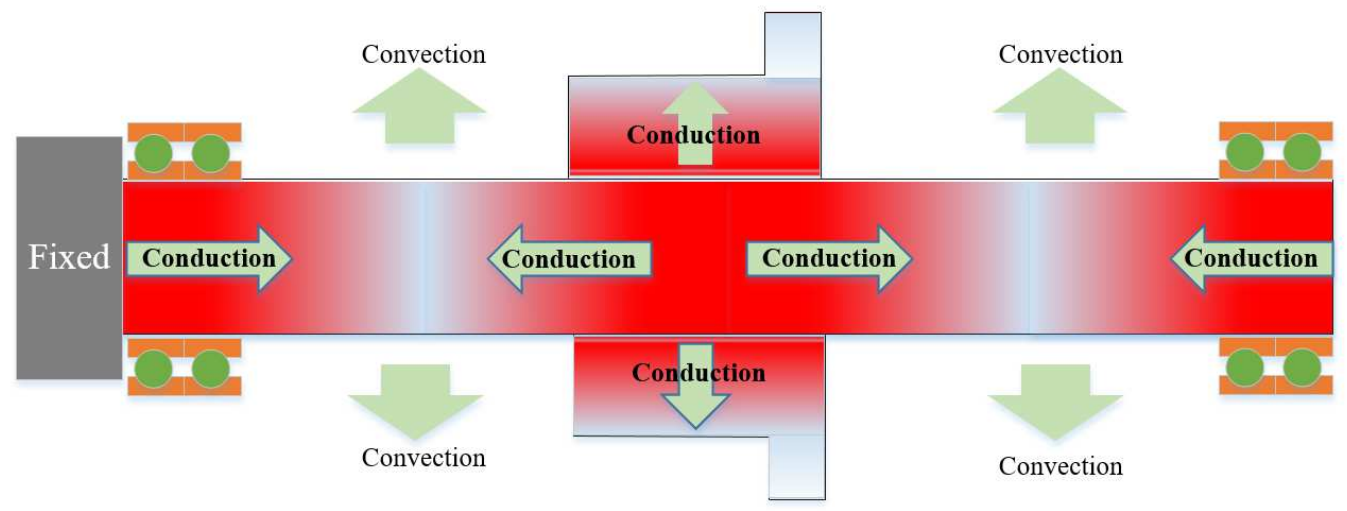

Fig.4 Two-dimensional heat transfer and temperature distribution of screw-nut feed system

As shown in Fig.4, the conduction distance should be considered because the nut and nut seat have a certain thickness, therefore, the temperature distribution of screwnut feed system is approximate to a two-dimensional heat transfer structure. The nut transmit process can simply to the structure as shown in Fig.5. Assuming the heat transfer between the nut and outside air is ignored, only the heat conduction between the upper and lower ends of the nut is considered. The heat transfer equation of the nut micro unit can be written as Eq.(3.11) then simplified into Eq.(3.15) through the Eq.( $3 \cdot 12-3 \cdot 14)$. 

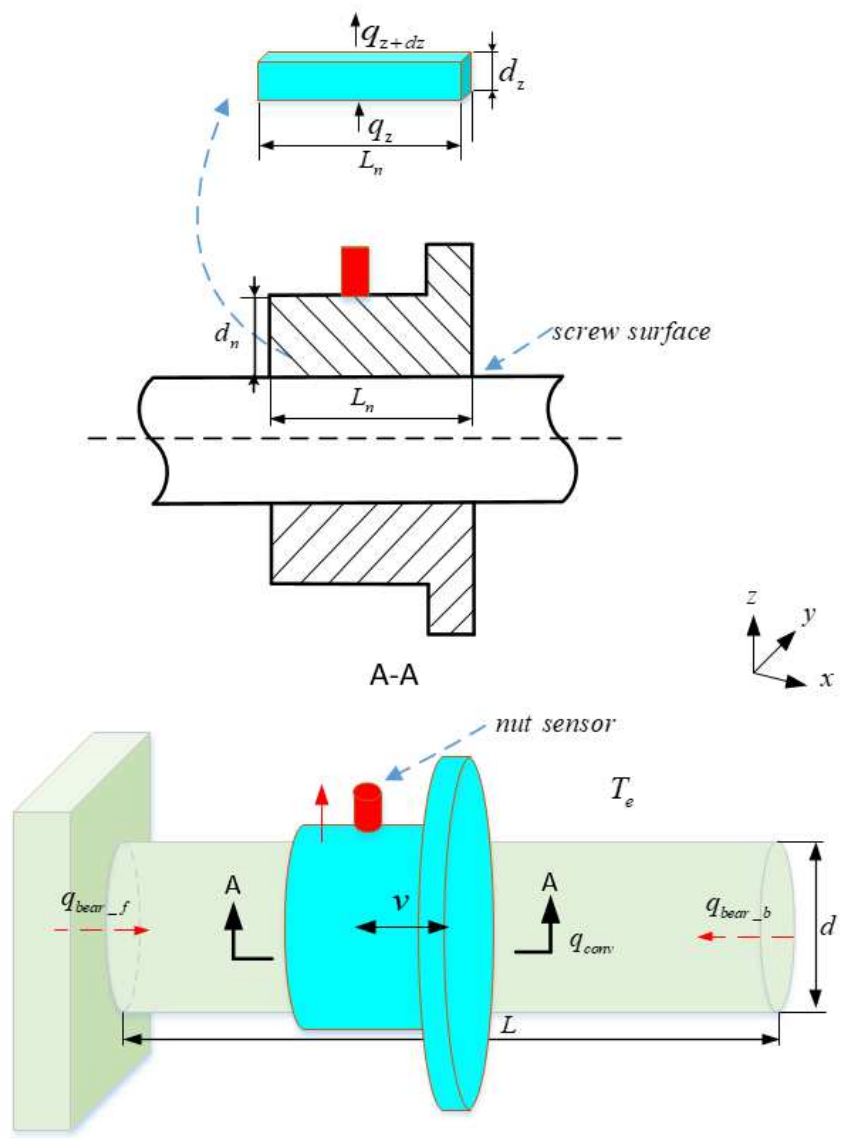

Fig.5 Thermal analysis of nut element

The heat balance equation in $\mathrm{Z}$ direction as Eq.(3.11):

$$
d Q_{t_{-} z}=Q_{i n_{-} z}-Q_{\text {out } z}
$$

The heat absorption rate of Z-direction micro unit as Eq.(3.12), $A_{c z}$ is the cross area of the nut.

$$
d Q_{t_{-} z}=q_{t_{-} z}=\rho c \frac{\partial T(x, z, t)}{\partial t} A_{c z} d z
$$

The input heat flow rate of $\mathrm{Z}$ direction micro unit as Eq.(3.13), $\lambda_{z}$ is the thermal conductivity of the screw.

$$
d Q_{i n_{-} z}=q_{z}=-\lambda_{z} A_{c n} \frac{\delta T(x, z, t)}{\delta z}
$$

The output heat flow rate of $\mathrm{Z}$-direction micro unit is:

$$
d Q_{\text {out } \_}=q_{\mathrm{z}+d z}=q_{\mathrm{z}}+\frac{d q_{z}}{d z} d z
$$

The simplified heat balance equation of micro unit in $\mathrm{Z}$ direction is:

$$
\lambda_{z} \frac{\partial^{2} T_{z}(x, z, t)}{\partial z^{2}}=\rho c \frac{\partial T_{z}(x, z, t)}{\partial t}
$$


Besides, Eq.(3.15) can be used to solve the temperature field distribution of nut block iteratively. The boundary conditions are shown in Eq.(3.16-3.17):

$$
\begin{gathered}
T_{z}\left(x, z_{i}, 1\right)=T_{e} \\
T_{z}\left(x, z_{0}, t\right)=\operatorname{mean}\left(T_{x}\left(\underset{i \in 1 \ldots N}{x_{i}}, t\right)\right)
\end{gathered}
$$

Where, $T_{z}\left(x, z_{i}, t\right)$ is the micro unit temperature of nut on the screw at time $t$. The average temperature $T_{z}\left(x, z_{0}, t\right)$ is taken as the temperature of lower surface contacting with the nut.

According to the screw and nut differential equation in Eq.(3.10) and Eq.(3.15), the two-dimensional thermal differential equation of screw-nut can be written as

$$
\left\{\begin{array}{l}
\lambda_{x} A_{c} \frac{\partial^{2} T(x, t)}{\partial x^{2}}=\rho c \frac{\partial T(x, t)}{\partial t} A_{c}+q(x, v) A_{s} \\
\lambda_{z} \frac{\partial^{2} T_{z}(x, z, t)}{\partial z^{2}}=\rho c \frac{\partial T_{z}(x, z, t)}{\partial t}
\end{array}\right.
$$

\subsection{Difference methods of two-dimensional thermal differential equation}

The solution of differential equation includes variable separation method and difference method, this paper uses difference method to solve the above problem[27]. As shown in Fig.6, the definite solution region is meshed with space step of $\Delta x$ and time step of $\Delta t$. The coordinates of nodes $(i, j)$ in this coordinate system are $\left(x_{i}, t_{j}\right)$, and $\mathrm{xi}_{\mathrm{i}}=\mathrm{i}$ $\Delta x, t_{j}=j \Delta t$, where $i=0,1,2, \cdots, \mathrm{m} ; j=0,1,2, \cdots, \mathrm{n}$.

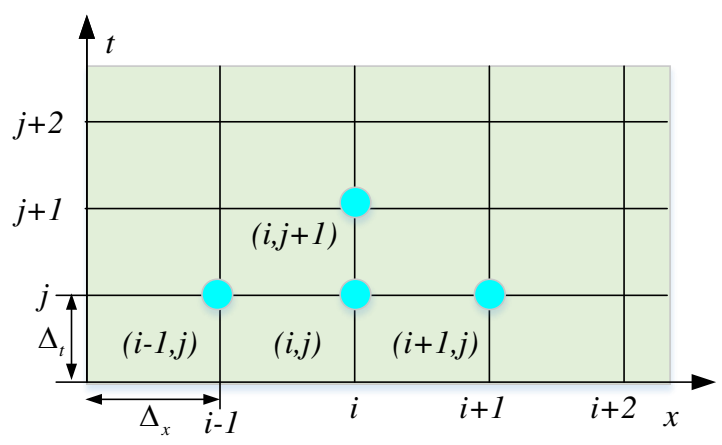

Fig.6 The scheme differential mesh of $T\left(x_{i}, t_{j}\right)$

The forward difference of the first-order partial differential and the central difference of the second-order partial differential are obtained as Eq.(3.19). 


$$
\left\{\begin{array}{l}
\left.\frac{\partial^{2}}{\partial x^{2}}\right|_{i, j}=\frac{T\left(x_{i+1}, t_{j}\right)-2 T\left(x_{i}, t_{j}\right)+T\left(x_{i-1}, t_{j}\right)}{\Delta x^{2}} \\
\left.\frac{\partial T}{\partial t}\right|_{i, j}=\frac{T\left(x_{i}, t_{j+1}\right)-T\left(x_{i}, t_{j}\right)}{\Delta t}
\end{array}\right.
$$

Supposing that:

$$
k_{1}=\frac{\lambda_{\mathrm{x}} A_{c}}{(\Delta x)^{2}}, k_{2}=\frac{\rho c A_{c}}{\Delta t}, k_{3}=\frac{\lambda_{\mathrm{z}}}{(\Delta z)^{2}}, k_{4}=\frac{\rho c}{\Delta t}
$$

According to Eq.(3.19), Eq.(3.18)can be transformed to:

$$
\left\{\begin{array}{l}
T\left(x_{i}, t_{j+1}\right)=T\left(x_{i-1}, t_{j}\right)+T\left(x_{i+1}, t_{j}\right)+\left(k_{2} / k_{1}-2\right) T\left(x_{i}, t_{j}\right)-A_{s} / k_{1} q(x, t) \\
T_{z}\left(x, z_{i}, t_{j+1}\right)=T_{z}\left(x, z_{i-1}, t_{j}\right)+T_{z}\left(x, z_{i+1}, t_{j}\right)+\left(k_{4} / k_{3}-2\right) T_{z}\left(x, z_{i}, t_{j}\right)
\end{array}\right.
$$

As the parameter $i$ could out of range at ends of the screw, so Eq.(3.20) needs to be considered separately at the leftmost and rightmost end of the screw.

\subsection{IPSOA}

\subsubsection{Objective optimization function}

The temperature of front, back bearing and nut namely $T_{f}, T_{b}, T_{n}$ can be obtained through the temperature sensors. The temperature at $i$ time is $T^{i}=\left[T_{f}^{i}, T_{b}^{i}, T_{n}^{i}\right]^{T}$. Further, the temperature value calculated by the above thermodynamic method is $\hat{T}^{i}=\left[\hat{T}_{f}^{i}, \hat{T}_{b}^{i}, \hat{T}_{n}^{i}\right]^{T}$. In order to minimize the error between the measured value and the predicted value, the objective function as Eq.(3.21).

\section{Objective function :}

$\min F\left(h, \lambda_{x}, \lambda_{z}, q_{\text {bearing_f }_{-}}, q_{\text {bearing }_{-} b}, q_{n u t}\right)=\sum_{i=1}^{N}\left[\left(T_{f}^{i}-\hat{T}_{f}^{i}\right)^{2}+\left(T_{b}^{i}-\hat{T}_{b}^{i}\right)^{2}+\left(T_{n}^{i}-\hat{T}_{n}^{i}\right)^{2}\right]$

S.t. :

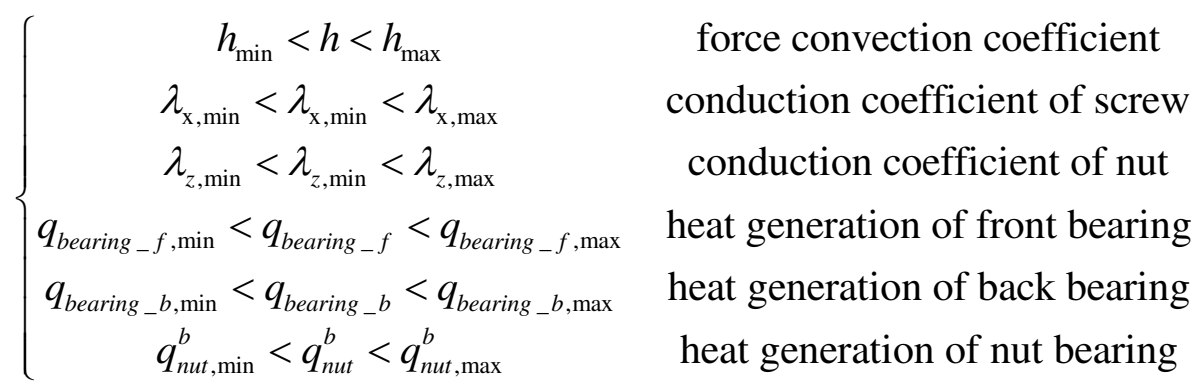

In order to optimize the thermal parameters of the above objective function, the 
IPSOA is adopted to solve this problem.

\subsubsection{IPSOA}

Table 1 Comparison between traditional PSO and IPSOA

\begin{tabular}{ccc}
\hline & PSO & IPSOA \\
\hline Weight update method & Calculation time is long with & Adaptive weight \\
& fixed weight & update \\
Particle search method & Easy fall into local optimization & \\
& with global search & Chaos search
\end{tabular}

As shown in Table 1, the traditional PSO algorithm has a slow convergence speed and easy to fall into local optimum, the IPSOA proposed in this paper has a good convergence speed and global optimization by using the adaptive weight update and chaos search, the calculation flow as shown in Fig.7.

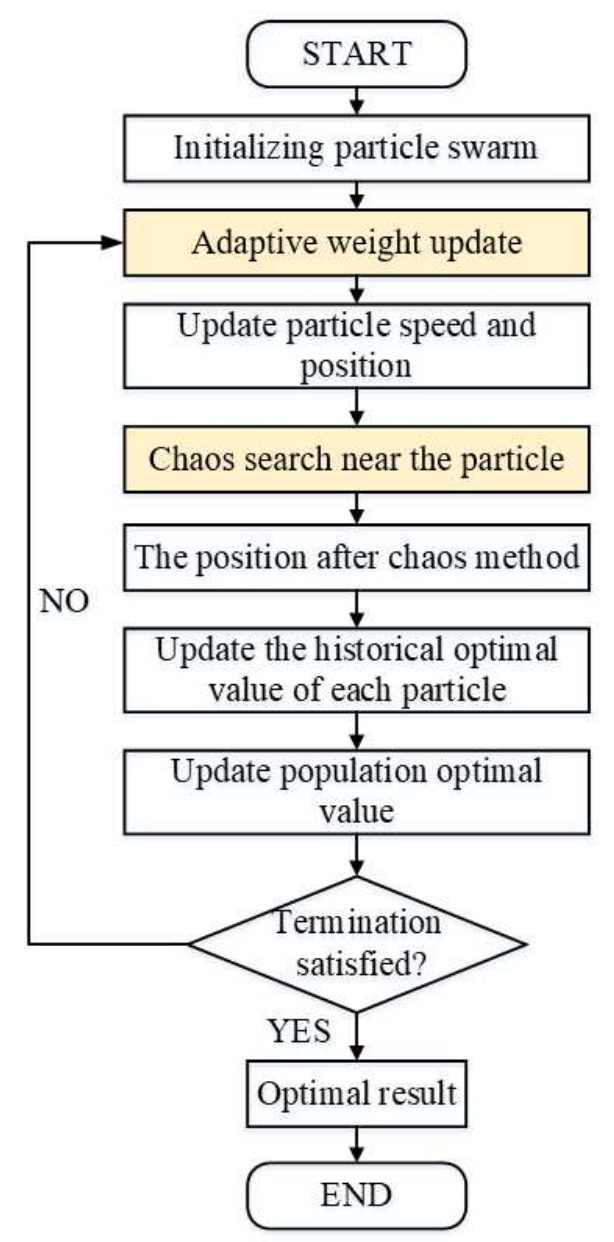

Fig.7 Process of IPSOA 
- Adaptive weight update

In order to solve the slow convergence rate of traditional PSO, a dynamic adaptive inertia weight coefficient is proposed[28]. The inverse S-shaped function is introduced to make the $w$ value at the initial stage of iteration have a large value, which ensures the algorithm has a strong global optimization ability at the initial stage of iteration, while has a small value for a long time in the later stage of iteration to increase the local optimization ability of the algorithm.

$$
w=w_{\max }-\left(w_{\max }-w_{\min }\right) \cdot \frac{1}{1+e^{a-b k}}
$$

Where $a=3.4, b=0.07, k$ is the current iteration number.

- Chaos search

Traditional PSO is easy to fall into local optimization, the randomness and regularity of chaotic motion can avoid particles falling into local optimum and improve the convergence speed and accuracy of the algorithm.

The main process of chaos search is to generate a group of random chaotic variables in the interval $[0,1]$ from Eq.(3.23), and then map the group of chaotic variables to the fitness of the particle according to Eq.(3.26). and then find the optimal solution as the individual history optimal value of the $i$ particle in generation $k$.

$$
\begin{gathered}
Z: a_{n+1}=u \cdot a_{n}\left(1-a_{n}\right) \\
R=\sqrt{\sum_{j=1}^{n}\left(V_{i}^{k}(j)\right)^{2}} \\
X_{i}^{k+1}=X_{i}^{k}+R \cdot\left(Z-\frac{1}{2}\right)
\end{gathered}
$$

Where $u$ is usually taken as $4, V_{i}^{k}(j)$ means the $J$-dimension belongs to the $k$ generation velocity of the $i$ particle. $X_{i}^{k}$ is the value of the position of the $i$ particle in the $k$ generation. The pseudo code of IPSOA is shown in Table 2.

Table 2 Pseudo code of IPSOA

\begin{tabular}{ll}
\hline 1 & Procedure PSO \\
\hline 2 & For each particle $i$ \\
3 & Initialize velocity $V_{i}$ and position $X_{i}$ for particle $i$ \\
\hline
\end{tabular}




\begin{tabular}{|c|c|}
\hline \multirow[t]{2}{*}{4} & End for \\
\hline & Weight $\boldsymbol{w}$ update \\
\hline \multirow[t]{2}{*}{5} & $g B e s t=\min \left\{p B e s t_{i}\right\}$ \\
\hline & While not stop \\
\hline 6 & For $i=1$ to $N$ \\
\hline 7 & Update the velocity and position of particle $i$ \\
\hline 8 & Chaos search near particle $i$ \\
\hline 9 & Evaluate particle $i$ \\
\hline 10 & If fit $\left(X_{i}\right)<$ fit $\left(g B e s t_{i}\right)$ \\
\hline 11 & $p B e s t i=X i$ \\
\hline 12 & If fit $\left(X_{i}\right)<\operatorname{fit}\left(g B e s t_{i}\right)$ \\
\hline 13 & $g B e s t_{i}=p$ Best $_{i}$ \\
\hline 14 & End for \\
\hline 15 & End while \\
\hline 16 & End procedure; \\
\hline
\end{tabular}

\subsection{Thermal error of screw}

As shown in the Fig.8, the screw is divided into $N$ units, and the deformation of each micro unit can be obtained by calculating the temperature $T\left(x_{i}, t_{j}\right)$. Supposing that the fixing mode of the screw is fixed at one end and extended freely at the other end. The thermal elongation at different position at any time is calculated as Eq. (3.26).

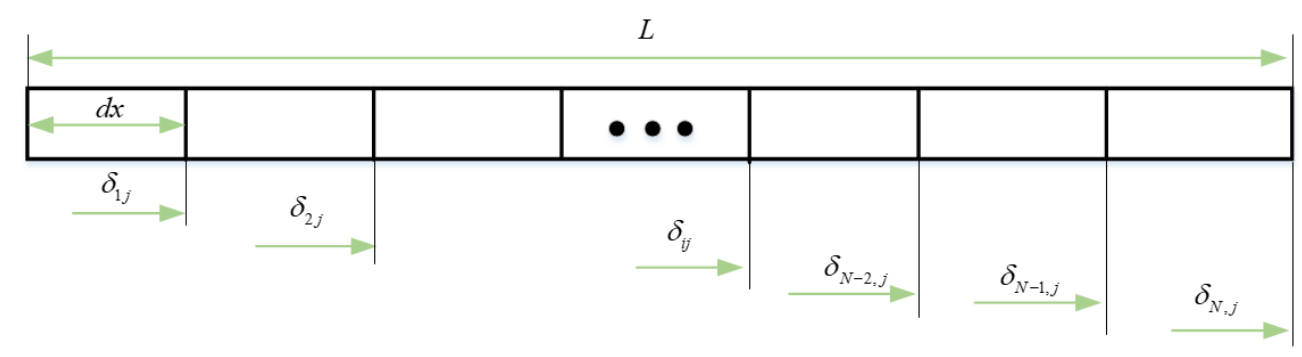

Fig.8 Screw deformation diagram of time $j$

$$
\begin{gathered}
\delta_{1 j}=\left(T\left(x_{1}, t_{j}\right)-T_{0}\right) \alpha d x \\
\delta_{2 j}=\left(T\left(x_{2}, t_{j}\right)-T_{0}\right) \alpha d x \\
\quad \ldots \\
\delta_{i j}=\left(T\left(x_{i}, t_{j}\right)-T_{0}\right) \alpha d x
\end{gathered}
$$


Where $\alpha$ is the thermal expansion coefficient of the screw and $t$ is the temperature distribution matrix. The total deformation of the screw at any position is as Eq.(3.27). Besides, $\alpha$ can be obtained according to the real measured thermal error and temperature.

$$
\Theta_{i j}=\sum_{i=1}^{M} \delta_{i j}=\sum_{i=1}^{M}\left(T\left(x_{i}, t_{j}\right)-T_{0}\right) \alpha d x
$$

\section{Experimental verification}

\subsection{Experimental environment}

\subsubsection{Screw-nut feed system}

The experimental data is collected on a vertical machining center(BM8-H) equipped with HNC848D CNC system in this paper. The structure of the screw is fixed at one end and moving at the other end, therefore, the thermal error is mainly extended in one direction. The main parameters are shown in Table3.

Table3 Parameters related to the screw-nut feed system

\begin{tabular}{cc}
\hline Parameters & Specification \\
\hline Length $(L)$ & $700 \mathrm{~mm}$ \\
Max moving range(S) & $500 \mathrm{~mm}$ \\
Fast speed $\left(v_{\max }\right)$ & $24 \mathrm{~m} / \mathrm{min}$ \\
Diameter $(d)$ & $40 \mathrm{~mm}$ \\
Lead $($ s $)$ & $12 \mathrm{~mm}$ \\
Length of nut $\left(L_{n}\right)$ & $50 \mathrm{~mm}$ \\
Thickness of the nut $\left(d_{n}\right)$ & $20 \mathrm{~mm}$ \\
\hline
\end{tabular}

\subsubsection{Temperature sensors}

According to the analysis above, the heat source of the feed screw mainly comes from the friction heat of the front, back bearing and screw-nut. Considering the mounting ability of the feed screw structure, temperature sensors were mounted near the front, back bearing and nut respectively as shown in Fig.9. The installation position of the nut temperature can affect the two-dimensional transfer structure proposed greatly in this paper. In addition, in order to analyse the influence of ambient temperature on thermal error, an additional sensor is mounted on the right end of the column to monitor the change of ambient temperature. 


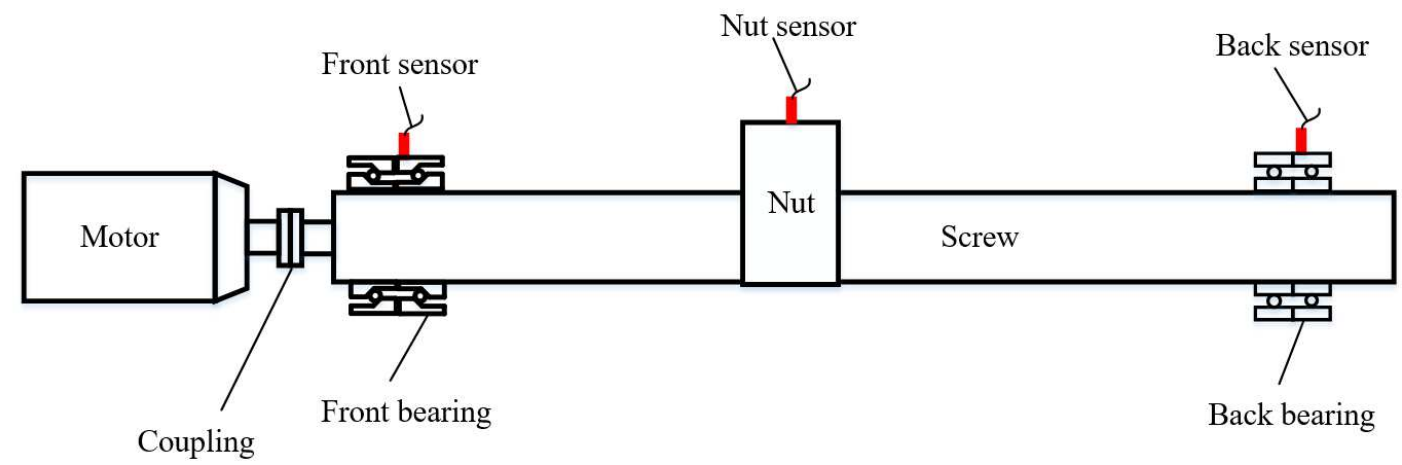

Fig.9 Mounting position of temperature sensors

\subsubsection{Data acquisition}

The data acquired in this paper mainly including the key points temperature and feed screw speed. All these data can be obtained through the open data acquisition interface for all users as shown in Fig.10, the frequency is $1 \mathrm{kHz}$. The temperature sensor is PT100 platinum resistance temperature sensor with an accuracy of $\pm 0.1^{\circ} \mathrm{C}$. Run a Zaxis heating $\mathrm{G}$ code and measure thermal deformation every 10 min after the machine is started. The thermal deformation was collected by Renishaw XM60 laser interferometer.

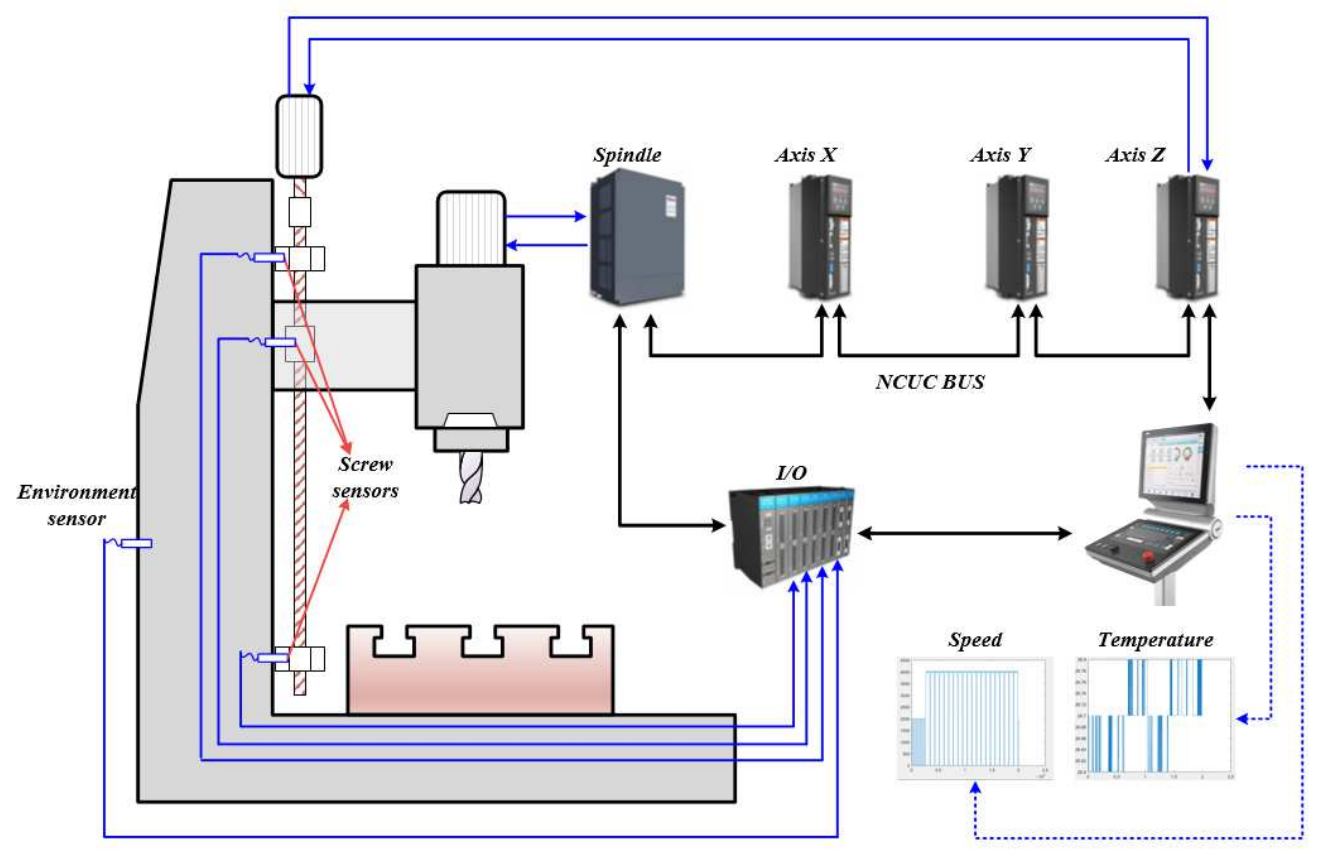

(a) Data acquisition of numerical control system 


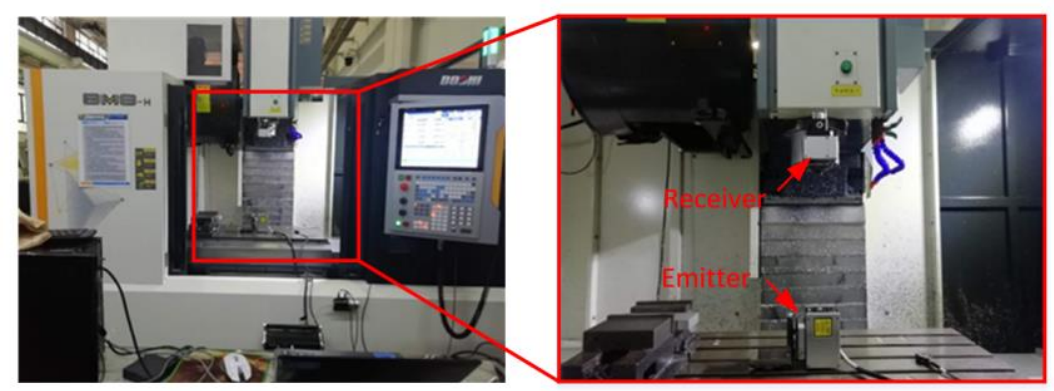

(b)Installation method of XM60 laser interferometer

Fig.10 Data acquisition of thermal error

\subsubsection{Experimental conditions}

In order to verify the thermal error modeling method proposed above, make Z-axis run at different speed with different moving range as shown in Table 4. According to the measurement standard of thermal deformation of machine tool mentioned in part VI of ISO230-3[29], each group of experiments was started after cooling for at least 8 hours. The speed of identification experiment is $8000 \mathrm{~mm} / \mathrm{min}$ and the moving range of parameter identification condition is $0-500 \mathrm{~mm}$. The data acquisition method is the same as mentioned in Section 4.1.4.

Table 4 Identification experiment condition

\begin{tabular}{cccc}
\hline Experiment group & $\begin{array}{c}\text { Speed } \\
(\mathrm{mm} / \mathrm{min})\end{array}$ & $\begin{array}{c}\text { Moving range } \\
(\mathrm{mm})\end{array}$ & $\begin{array}{c}\text { Running time } \\
(\mathrm{min})\end{array}$ \\
\hline Identification experiment & 8000 & $0-500$ & 90 \\
\hline
\end{tabular}

The working condition of predict experiment of different speed and moving range is shown in Table 5 .

Table 5 Predict experiment condition

\begin{tabular}{cccc}
\hline Experiment group & $\begin{array}{c}\text { Speed } \\
(\mathrm{mm} / \mathrm{min})\end{array}$ & $\begin{array}{c}\text { Moving range } \\
(\mathrm{mm})\end{array}$ & $\begin{array}{c}\text { Running time } \\
(\mathrm{min})\end{array}$ \\
\hline Predict experiment 1\# & 8000 & $0-200$ & 90 \\
\hline Predict experiment 2\# & 4000 & $0-500$ & 90 \\
\hline Predict experiment 3\# & 6000 & $200-400$ & 90 \\
\hline
\end{tabular}

\subsubsection{Initial parameters}

The software used in the process of parameter identification and establishment of 
thermal error model is MATLAB. It is necessary to set the basic thermal parameters of the screw before the model training as shown in Table 6 .

Table 6 Basic parameters of screw thermodynamic model

\begin{tabular}{cccc}
\hline Parameter & Heat capacity $(c)$ & Time step $(\Delta t)$ & Space step $\left(\Delta_{X}\right)$ \\
\hline Value & $448 \mathrm{~J} /\left(\mathrm{kg} \cdot{ }^{\circ} \mathrm{C}\right)$ & $0.1 \mathrm{~s}$ & $0.1 \mathrm{~mm}$
\end{tabular}

In addition, the selected particle swarm optimization parameters to initialize the model are shown in Table 7.

Table 7 Hyperparameters of PSO

\begin{tabular}{cccccc}
\hline Parameter & $\begin{array}{c}\text { Initial } \\
\text { population }\end{array}$ & $\begin{array}{c}\text { Search } \\
\text { space }\end{array}$ & Epochs & $\begin{array}{c}\text { Learning } \\
\text { factor } c_{1}\end{array}$ & $\begin{array}{c}\text { Learning } \\
\text { factor } c_{2}\end{array}$ \\
\hline Value & 50 & 5 & 50 & 1.5 & 2.5 \\
\hline
\end{tabular}

For the objective function of Eq.(3.21), the thermal characteristics constraints are given as follows

$$
\left\{\begin{array}{c}
3<h<20 \\
40<\lambda_{\mathrm{x}, \min }<50 \\
30<\lambda_{\mathrm{x}, \min _{1}}<40 \\
0<q_{\text {bearing }_{f}}<5 \\
0<q_{\text {bearing }_{-} b}<5 \\
1<q_{\text {nut }}^{b}<10
\end{array}\right.
$$

\subsection{Experimental results}

\subsubsection{Parameter Identification}

The thermodynamic parameters are identified by using the experimental data in Table 4. The temperature measured by three sensors are shown in Fig.11. 


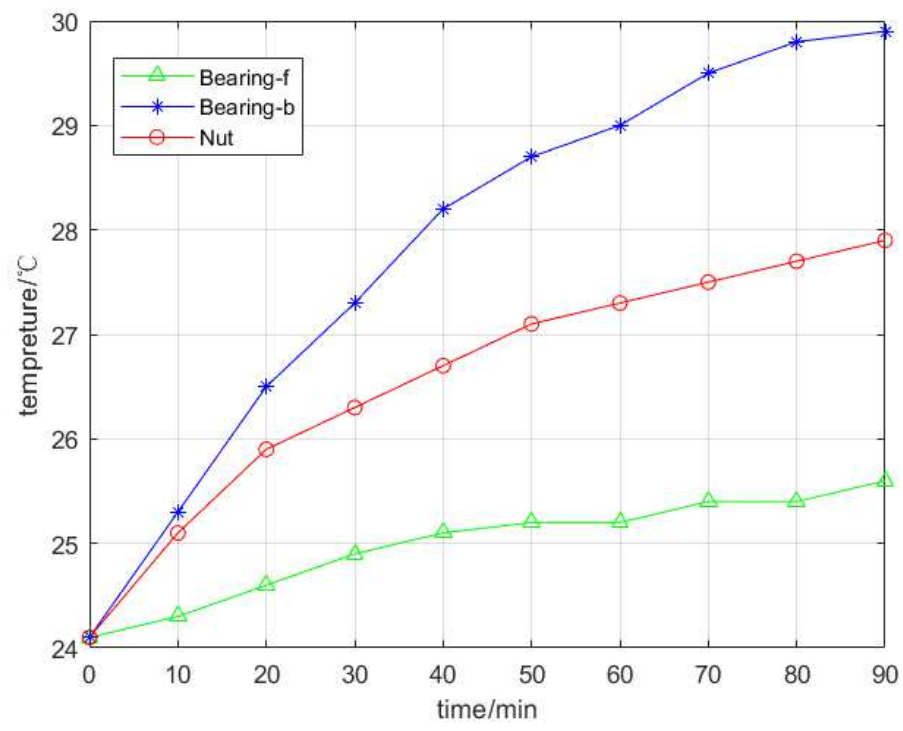

Fig.11 Temperature diagram of screw measuring point

The temperature of the measuring points and the initial parameters referring to the two-dimensional thermal differential equation are brought into the optimization function in Eq.(3.21). The identified results of PSO and IPSOA are shown in Fig.12.

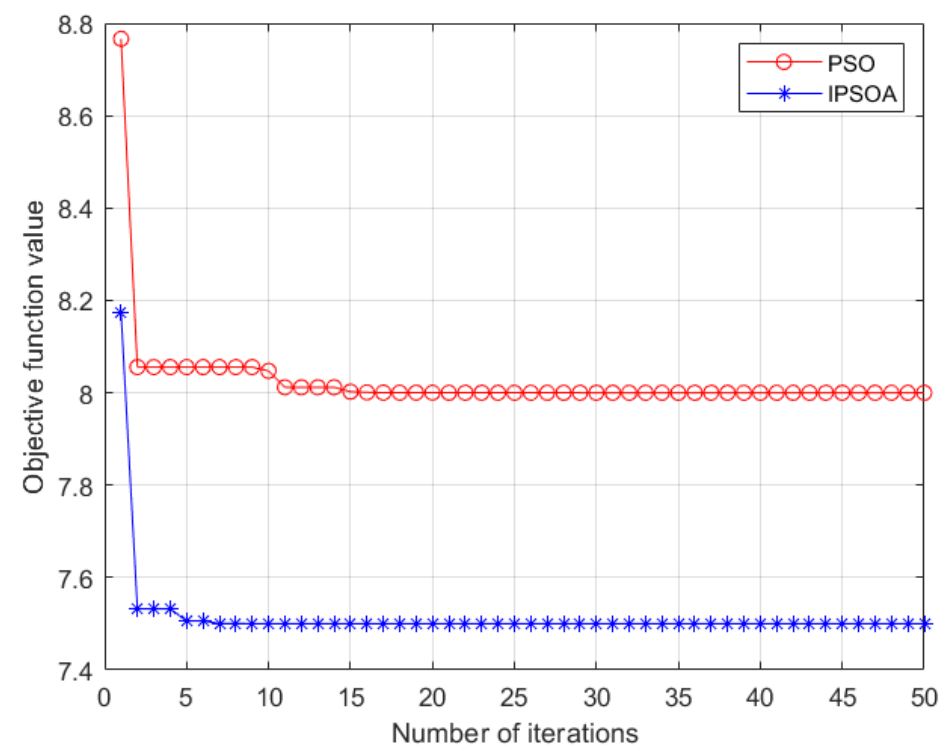

Fig.12 Temperature diagram of screw measuring point Table 8 Parameter identified by IPSOA

\begin{tabular}{lcc}
\hline & PSO & IPSOA \\
\hline Iterations & 15 & 5 \\
Fit value & 8.0 & 7.5
\end{tabular}

As can be seen from the Fig.12 and Table 8, IPSOA has certain advantages in 
convergence speed and optimization results. PSO needs 15 iterations to find the optimal solution and fall into the local optimal twice, while IPSOA can jump out of the local optimal by chaos search method, besides, it only takes 5 iterations to find the global optimal solution. The identified thermal parameters by using the IPSOA are shown in Table 9. The identified parameters are different from the real . Furthermore, $q_{n u t}$ under different feed speed can be calculated by Eq.(3.4-3.5).

Table 9 Parameter identified by IPSOA

\begin{tabular}{cccccc}
\hline$h$ & $\lambda_{x}$ & $\lambda_{z}$ & $q_{\text {bearing } f}$ & $q_{\text {bearing_b }}$ & $q_{\text {nut }}^{b}$ \\
$\left(W / m^{2} \cdot K\right)$ & $(W /(m \cdot K))$ & $(W /(m \cdot K))$ & $(W)$ & $(W)$ & $(W)$ \\
\hline 8.5 & 50 & 45 & 1.1 & 0.8 & 4.2 \\
\hline
\end{tabular}

\subsubsection{Results of TDM}

The temperature and thermal deformation of lead screw at different time and position can be obtained through the TDM model. The simulation result of identification experiment is shown in Fig.13-14.

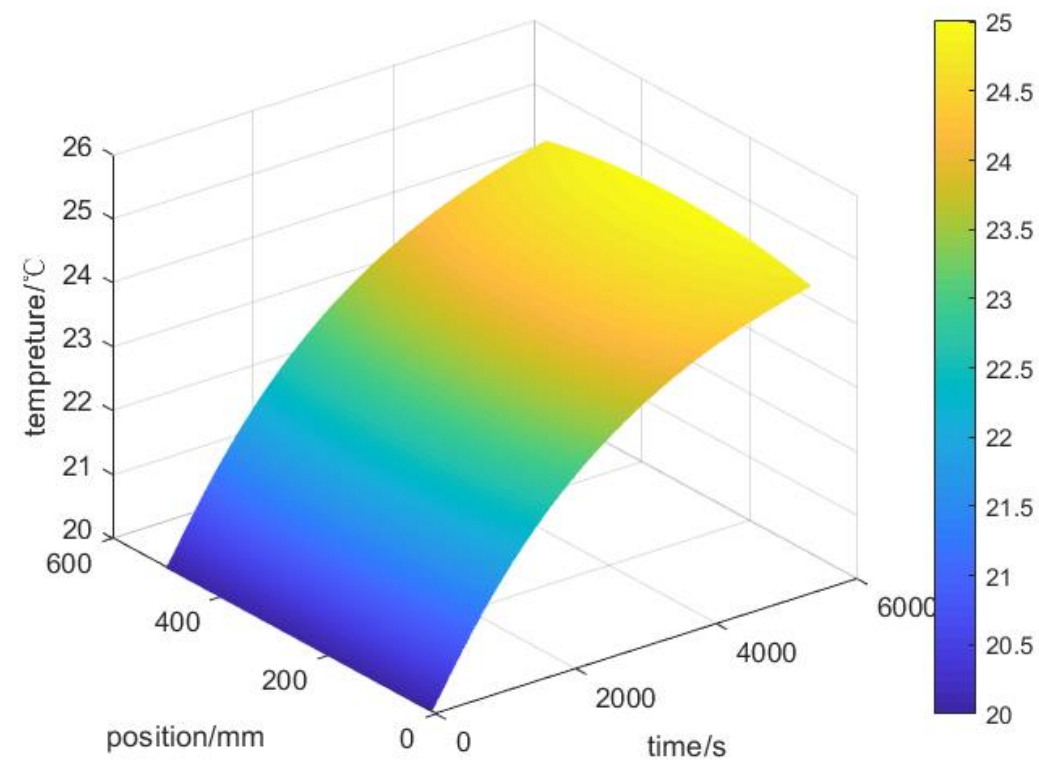

Fig.13 Temperature under different position and time

It can be seen from Fig. 13 that the temperature increases with the increase of time. The heat balance time of the screw is about $70 \mathrm{~min}$ and the corresponding temperature rise is about $6^{\circ} \mathrm{C}$ 。 


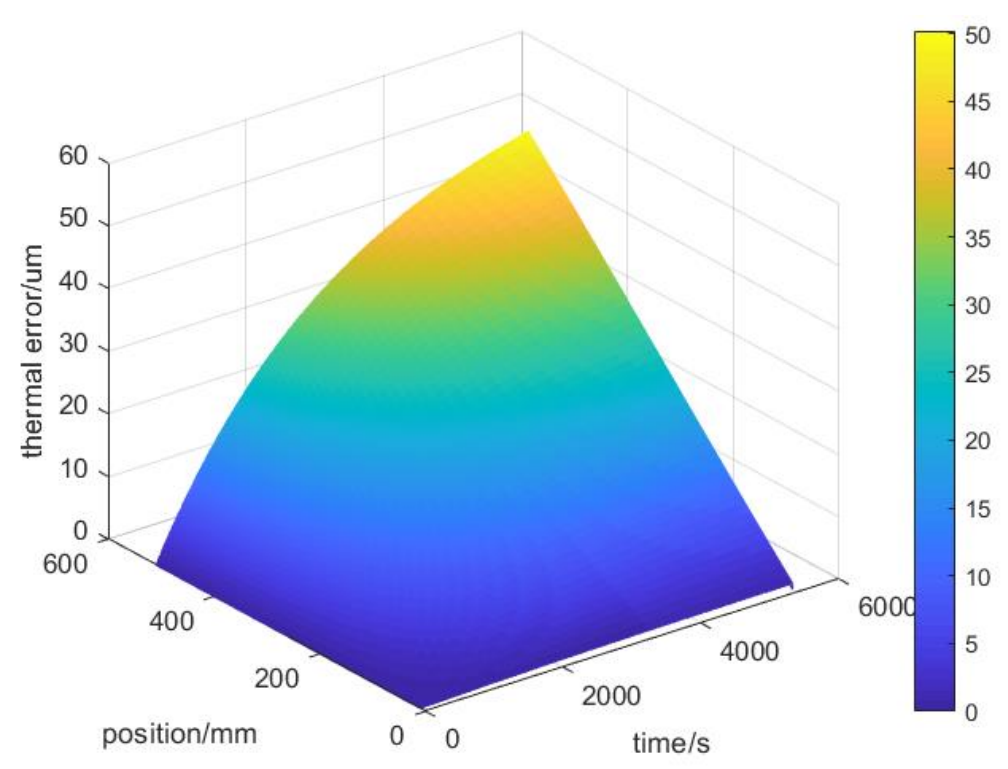

Fig.14 Thermal error under different position and time

It can be seen from Fig.14 that the deformation increases the distance from the fixed point, the maximum deformation is at the free end of the Z-axis screw.

\subsubsection{Performance of TDM under different condition}

In order to further verify the effectiveness of the proposed TDM method for different working conditions, three groups of experimental conditions were conducted, the final forecast residual error is shown in Fig.15-17.
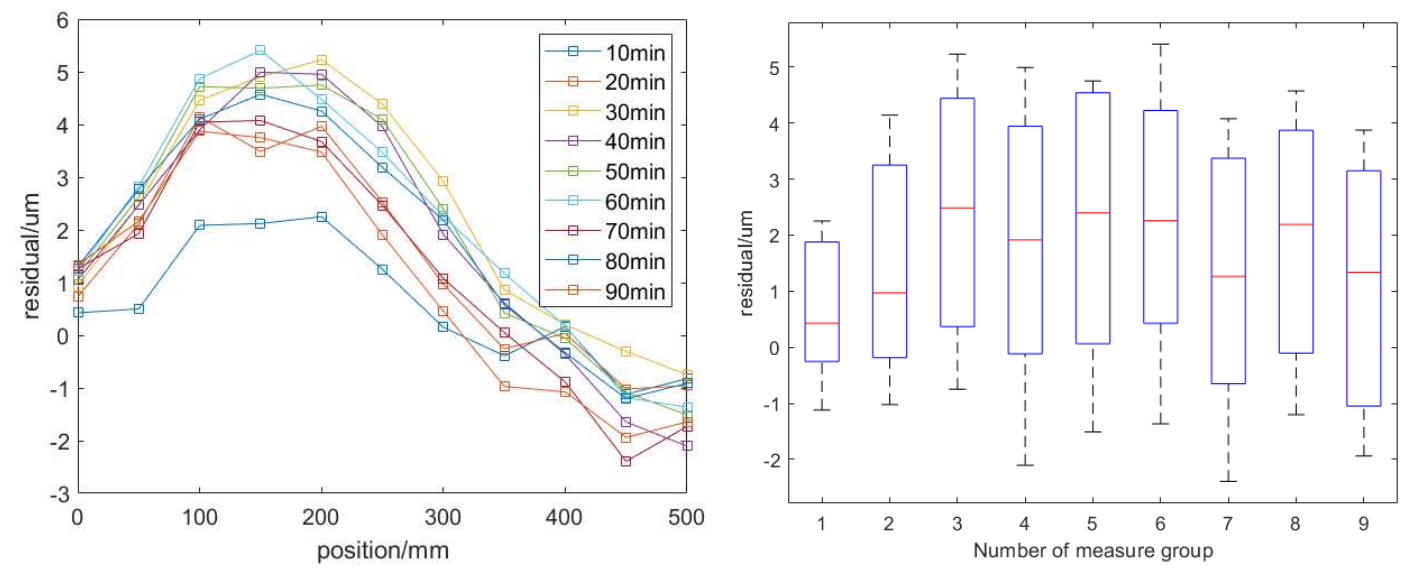

Fig.15 Residual of predict experiment 1\#

The running speed of experiment $1 \#$ is $8000 \mathrm{~mm} / \mathrm{min}$, the moving range is $0-200$ $\mathrm{mm}$, and the fitting residual error is between $[-1,3] \mathrm{um}$. Compared with the identification working condition, it is proved that the TDM method proposed in this paper has a good fitting effect for different moving range. 

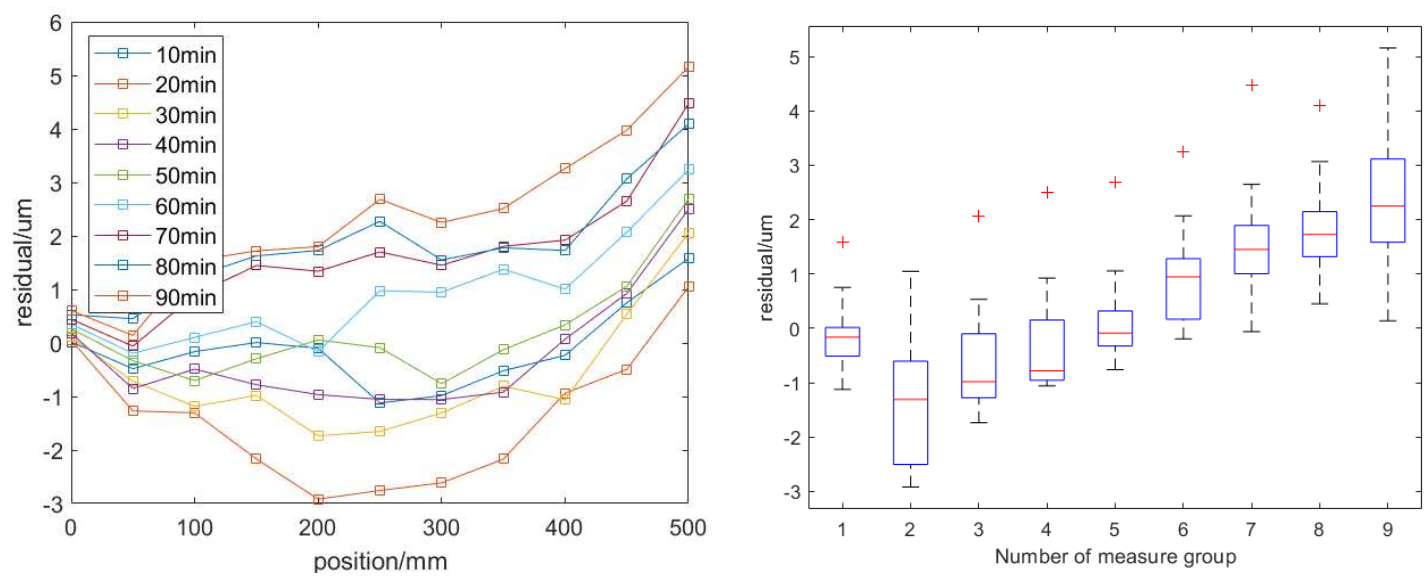

Fig.16 Residual of predict experiment 2\#

The feed speed of experiment $2 \#$ is $4000 \mathrm{~mm} / \mathrm{min}$, the moving range is $0-500 \mathrm{~mm}$, and the fitting residual error is between $[-2,4]$ um. Compared with the identification working condition, it shows that the proposed TDM method has good fitting effect for different speeds.
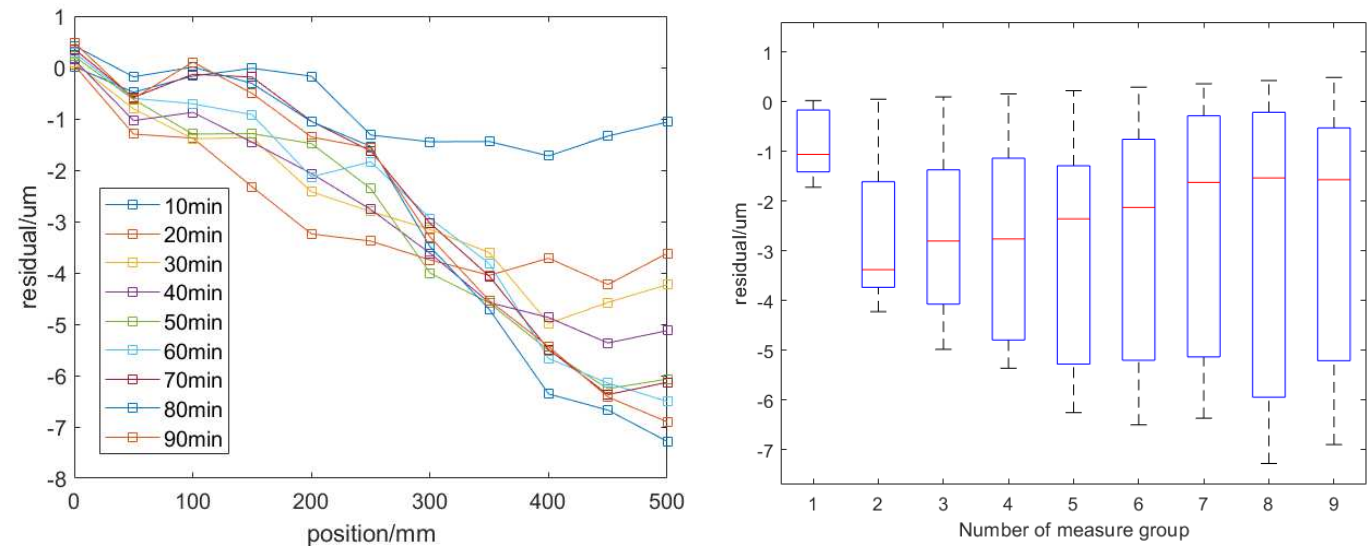

Fig.17 Residual of predict experiment 3\#

The feed speed of experiment $3 \#$ is $6000 \mathrm{~mm} / \mathrm{min}$, the moving range is 200-400 $\mathrm{mm}$ and the fitting residual error is between $[-3.5,0.1] \mathrm{um}$. Compared with the previous two groups of experimental conditions, it is proved that the proposed TDM method has good fitting effect for different speeds and different moving range.

Moreover, the maximum predicted error (MPE), root mean-square error (RMSE) and accuracy $(\mathrm{AC})$ were used to measure the prediction accuracy of the thermal error modeling method in this paper. The calculation formulas are shown in Eq.(4.1) (4.3). The prediction results of three groups of working condition are evaluated by MPE, RMSE, AC and the results are shown in Table 10. $E_{\max }$ is the measured maximum error. 


$$
\begin{gathered}
M P E=\max \left(E_{\text {actual }}-E_{\text {predict }}\right) \\
R M S E=\sqrt{\frac{1}{N} \sum_{t=1}^{N}\left(E_{\text {actual }}-E_{\text {predict }}\right)^{2}} \\
A C=\frac{\sqrt{\frac{1}{N} \sum_{t=1}^{N}\left(E_{\text {actual }}-E_{\text {predict }}\right)^{2}}}{E_{\max }} \times 100 \%
\end{gathered}
$$

Table 10 Evaluation of prediction results

\begin{tabular}{rcccc}
\hline & $E_{\max }(\mathrm{um})$ & MPE (um) & RMSE (um) & $A C(\%)$ \\
\hline Predict experiment 1\# & 39 & 5.1 & 3.6 & 90.7 \\
Predict experiment 2\# & 43 & 5.0 & 3.8 & 91.1 \\
Predict experiment 3\# & 36 & 7.2 & 4.2 & 88.3 \\
\hline
\end{tabular}

It can be seen from Table 10 that the MPE of TDM for different speeds and different moving range is within $7.2 \mathrm{um}$, the corresponding predict accuracy can reach $88.3 \%$, which has high precision and can satisfy the actual compensation needs.

\subsubsection{Comparison between ODM and TDM}

In order to compare with the prediction effect of ODM, the data of predict experiment $1 \#$ were used to predict the thermal error by ODM.

Table 11 Comparison between ODM and TDM

\begin{tabular}{cccccc}
\hline \multicolumn{2}{c}{ MPE(um) } & \multicolumn{2}{c}{$R M S E(u m)$} & \multicolumn{2}{c}{$A C(\%)$} \\
\hline$O D M$ & $T D M$ & $O D M$ & $T D M$ & $O D M$ & $T D M$ \\
6.2 & 5.1 & 5.3 & 3.6 & 86.4 & 90.7 \\
\hline
\end{tabular}

It can be seen from Table 10 that the maximum measured thermal error is $39 \mathrm{um}$. As shown in Table 11, the MPE of the two methods is $6.2 \mathrm{um}$ and $5.1 \mathrm{um}$ respectively. The RMSE of the thermal error modeling by TDM is $3.6 \mathrm{um}$ while the ODM is $5.3 \mathrm{um}$. The corresponding predict accuracy of TDM is $90.7 \%$ while the ODM is $86.4 \%$. The above result proves that the TDM has advantage over ODM with good accuracy.

\section{Discussions}

As shown in Fig.15-17 and Table 10, the proposed thermal error model considering the two-dimensional thermal characteristics have achieved a certain prediction accuracy. 
But still some questions need to be discussed.

1) There is a certain gap between the established simplified model and the real model in this paper. The screw and nut regard as a one-dimensional respectively exists a difference because the size of the shoulder at both ends of the screw and structure of the screw groove is ignored. In addition, the influence of the cooling and lubrication conditions have effect on the model.

2) The influence of external heat source on the screw is not considered. The experiment is not carried out in constant temperature workshop, so the change of the ambient temperature will lead to the deformation of the machine tool structure, and the actual measurement of the screw thermal error includes part of the structural deformation.

\section{Conclusions}

In order to reduce the influence of thermal error on the screw, this paper takes the screw-nut feed system as the research object to establish the corresponding thermal error model, the relative error between predicted and measured data is within $7.2 \mathrm{um}$, the conclusions are as follows:

1) Considering the conduction distance between the screw and nut is more consistent with the actual heat conduction model. The heating model of screw-nut feed system is a complex structure system mainly composed of screw and nut. The accuracy of the model can be improved by considering the size of nut structure when the temperature of measuring point on nut is used to identify the thermal characteristic parameters.

2) Using the IPSOA can improve the accuracy of thermal error prediction. The IPSOA proposed in this paper can not only avoid falling into the local optimal solution, but also converge fast while optimizing the thermal boundary conditions of screw-nut system.

3) The thermodynamic model combined with fixed point temperature value can be used to calculate the thermal error of the screw. Compared with the traditional datadriven model, it does not need to spend time looking for temperature sensitive points. It is suitable for thermal error modeling and compensation of machine parts or the 
whole machine, which has a certain application prospect.

\section{-Ethical Approval}

Not applicable

\section{-Consent to Participate}

All authors are agreed to participate

\section{-Consent to Publish}

Written informed consent for publication was obtained from all participants

\section{-Authors Contributions}

Chen Yu: Completed thermal error experiment design, data acquisition and model establishment

Guangda Xu: Complete the formulation of the paper framework and the experimental conclusion

Jihong Chen: Review the paper as a whole

\section{-Funding}

This paper is supported by the National Science and Technology major projects-Research and application verification of new generation intelligent $\mathrm{HNC} 9 \mathrm{CNC}$ system[Grant Number 2018ZX04035002-002], which is main accomplished by Guangda Xu. The other project is National Natural Science Foundation of China--Tool life model of whole process flow based on cutting big data [Grant Number 51675204], which is main accomplished by Jihong Chen.

\section{-Competing Interests}

The authors declare that they have no competing financial interests

\section{-Availability of data and materials}

The datasets used or analysed during the current study are available from the corresponding author on reasonable request.

\section{References}

[1] J. Mayr et al., "Thermal issues in machine tools," CIRP Ann., vol. 61, no. 2, pp. 771-791, 2012, doi: https://doi.org/10.1016/j.cirp.2012.05.008.

[2] W. . Lei and Y.. Hsu, "Accuracy enhancement of five-axis CNC machines 
through real-time error compensation," Int. J. Mach. Tools Manuf., vol. 43, no. 9, pp. 871-877, Jul. 2003, doi: 10.1016/S0890-6955(03)00089-0.

[3] X. Thiem, B. Kauschinger, and S. Ihlenfeldt, "Structure Model Based Correction of Thermally Induced Motion Errors of Machine Tools," Procedia Manuf., vol. 14, pp. 128-135, 2017, doi: https://doi.org/10.1016/j.promfg.2017.11.015.

[4] Z. Z. Xu, X. J. Liu, and S. K. Lyu, "Study on positioning accuracy of nut/shaft air cooling ball screw for high-precision feed drive," Int. J. Precis. Eng. Manuf., vol. 15, no. 1, pp. 111-116, 2014, [Online]. Available: 10.1007/s12541-013-0312-7.

[5] X. Wei, F. Gao, Y. Li, and D. Zhang, "Thermal Errors Classification Compensation without Sensor for CNC Machine Tools," Math. Probl. Eng., vol. 2018, p. 5752932, 2018, doi: 10.1155/2018/5752932.

[6] J. Vyroubal, "Compensation of machine tool thermal deformation in spindle axis direction based on decomposition method," Precis. Eng., vol. 36, no. 1, pp. 121-127, 2012, doi: 10.1016/j.precisioneng.2011.07.013.

[7] F. Tan, M. Yin, L. Wang, and G. Yin, "Spindle thermal error robust modeling using LASSO and LS-SVM," Int. J. Adv. Manuf. Technol., vol. 94, no. 5, pp. 2861-2874, 2018, doi: 10.1007/s00170-017-1096-1.

[8] A. M. Abdulshahed, A. P. Longstaff, and S. Fletcher, "The application of ANFIS prediction models for thermal error compensation on CNC machine tools," Appl. Soft Comput., vol. 27, pp. 158-168, 2015, doi: https://doi.org/10.1016/j.asoc.2014.11.012.

[9] J. Zapłata and M. Pajor, "Piecewise compensation of thermal errors of a ball screw driven CNC axis,” Precis. Eng., vol. 60, no. July, pp. 160-166, 2019, doi: 10.1016/j.precisioneng.2019.07.011.

[10] J. Han, L. Wang, H. Wang, and N. Cheng, "A new thermal error modeling method for CNC machine tools," Int. J. Adv. Manuf. Technol., vol. 62, no. 1, pp. 205-212, 2012, doi: 10.1007/s00170-011-3796-2.

[11] H. Yang, R. Xing, and F. Du, "Thermal error modelling for a high-precision 
feed system in varying conditions based on an improved Elman network," Int. J. Adv. Manuf. Technol., vol. 106, no. 1, pp. 279-288, 2020, doi: 10.1007/s00170-019-04605-1.

[12] R. Ramesh, M. A. Mannan, A. N. Poo, and S. S. Keerthi, "Thermal error measurement and modelling in machine tools. Part II. Hybrid Bayesian Network-support vector machine model," Int. J. Mach. Tools Manuf., vol. 43, no. 4, pp. 405-419, 2003, doi: https://doi.org/10.1016/S0890-6955(02)00264$\mathrm{X}$.

[13] H. Yang and J. Ni, "Dynamic modeling for machine tool thermal error compensation," J. Manuf. Sci. Eng. Trans. ASME, vol. 125, no. 2, pp. 245-254, 2003, doi: 10.1115/1.1557296.

[14] T. jun Li, C. yu Zhao, and Y. min Zhang, "Prediction method of thermal errors of the screw system in lathes based on moving thermal network," Precis. Eng., vol. 59, no. January, pp. 166-173, 2019, doi:

10.1016/j.precisioneng.2019.07.001.

[15] J. Zapłata and M. Pajor, "Piecewise compensation of thermal errors of a ball screw driven CNC axis," Precis. Eng., vol. 60, no. August, pp. 160-166, 2019, doi: 10.1016/j.precisioneng.2019.07.011.

[16] K. Liu, J. Wu, H. Liu, M. Sun, and Y. Wang, "Reliability analysis of thermal error model based on DBN and Monte Carlo method," Mech. Syst. Signal Process., vol. 146, p. 107020, 2021, doi: 10.1016/j.ymssp.2020.107020.

[17] N. S. Mian, S. Fletcher, A. P. Longstaff, and A. Myers, "Efficient estimation by FEA of machine tool distortion due to environmental temperature perturbations," Precis. Eng., vol. 37, no. 2, pp. 372-379, 2013, doi: 10.1016/j.precisioneng.2012.10.006.

[18] H. Shi, C. Ma, J. Yang, L. Zhao, X. Mei, and G. Gong, "Investigation into effect of thermal expansion on thermally induced error of ball screw feed drive system of precision machine tools," Int. J. Mach. Tools Manuf., vol. 97, pp. 60-71, 2015, doi: 10.1016/j.ijmachtools.2015.07.003.

[19] T. jun Li, C. yu Zhao, and Y. min Zhang, "Adaptive real-time model on 
thermal error of ball screw feed drive systems of CNC machine tools," Int. J. Adv. Manuf. Technol., vol. 94, no. 9-12, pp. 3853-3861, 2018, doi: 10.1007/s00170-017-1076-5.

[20] S. Huang, P. Feng, C. Xu, Y. Ma, J. Ye, and K. Zhou, "Utilization of heat quantity to model thermal errors of machine tool spindle," Int. J. Adv. Manuf. Technol., vol. 97, no. 5, pp. 1733-1743, 2018, doi: 10.1007/s00170-018-20515.

[21] J. Kennedy and R. Eberhart, "Particle swarm optimization," in Proceedings of ICNN'95 - International Conference on Neural Networks, 1995, vol. 4, pp. 1942-1948 vol.4, doi: 10.1109/ICNN.1995.488968.

[22] J. Kennedy and R. C. Eberhart, "A discrete binary version of the particle swarm algorithm," in 1997 IEEE International Conference on Systems, Man, and Cybernetics. Computational Cybernetics and Simulation, 1997, vol. 5, pp. 4104-4108 vol.5, doi: 10.1109/ICSMC.1997.637339.

[23] H. Pan, L. Wang, and B. Liu, "Particle swarm optimization for function optimization in noisy environment," Appl. Math. Comput., vol. 181, no. 2, pp. 908-919, 2006, doi: https://doi.org/10.1016/j.amc.2006.01.066.

[24] S. Xuegang, Y. Chao, C. Yihui, and A. Zhengang, "Controlling Chaos by PSOBased Neural Network," in 2009 International Conference on Intelligent Human-Machine Systems and Cybernetics, 2009, vol. 1, pp. 249-252, doi: 10.1109/IHMSC.2009.70.

[25] R. Fierro, O. Castillo, and F. Valdez, "Optimization of fuzzy control systems with different variants of Particle Swarm Optimization," in 2013 IEEE Workshop on Hybrid Intelligent Models and Applications (HIMA), 2013, pp. 51-56, doi: 10.1109/HIMA.2013.6615022.

[26] F. Valdez, P. Melin, and O. Castillo, “An improved evolutionary method with fuzzy logic for combining Particle Swarm Optimization and Genetic Algorithms," Appl. Soft Comput., vol. 11, no. 2, pp. 2625-2632, 2011, doi: https://doi.org/10.1016/j.asoc.2010.10.010.

[27] C. Jin, B. Wu, Y. Hu, P. Yi, and Y. Cheng, "Thermal characteristics of a CNC 
feed system under varying operating conditions," Precis. Eng., vol. 42, pp. 151-164, 2015, doi: 10.1016/j.precisioneng.2015.04.010.

[28] Y. Li, J. Liu, and Y. Wang, "An adaptive weight PSO for rolling schedules multi-objective optimization of tandem cold rolling," Proc. 2009 IEEE Int. Conf. Autom. Logist. ICAL 2009, no. 20060145025, pp. 895-899, 2009, doi: 10.1109/ICAL.2009.5262796.

[29] ISO, "ISO230-3 Test code for machine tools part 3: Determination of thermal effect.” ISO, Geneva,Switzerland, 2007. 
Figures

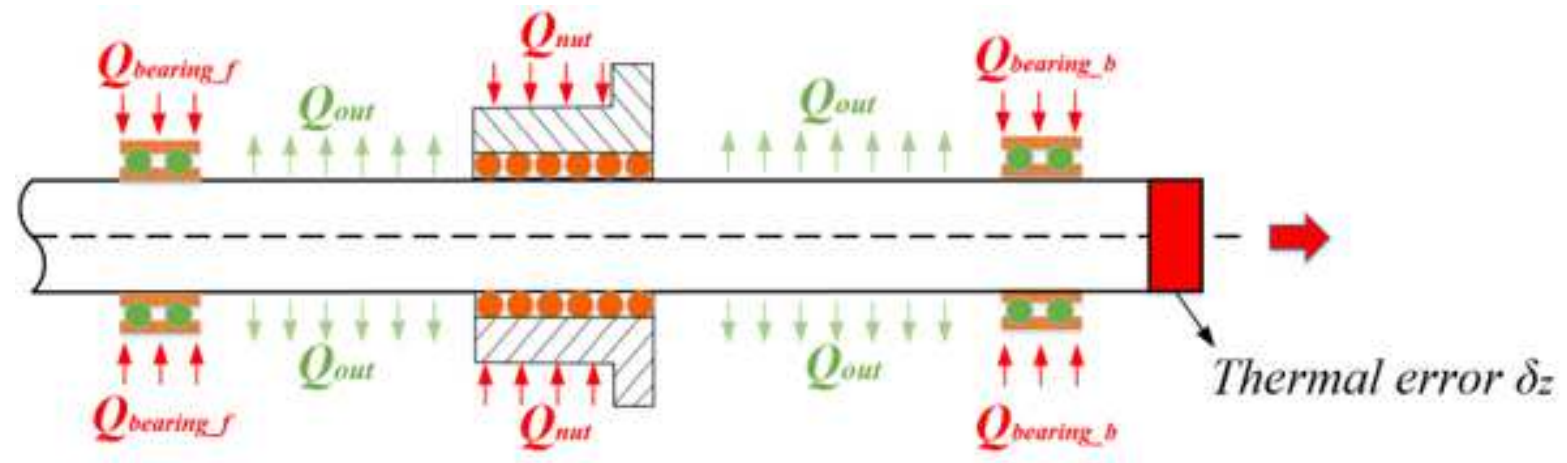

Figure 1

Causes of thermal deformation relating to feed screw 


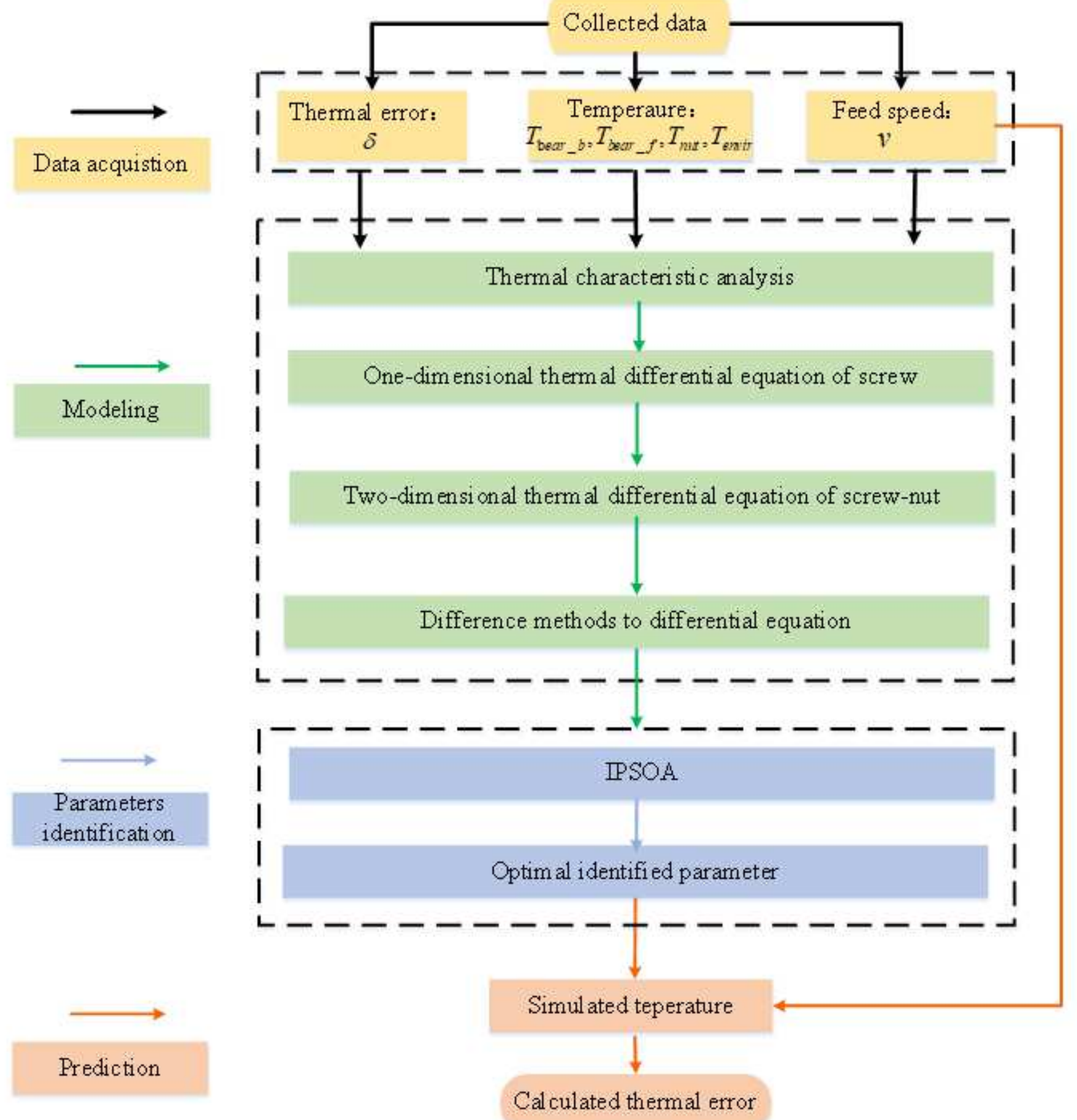

Figure 2

Process of thermal error modeling method 


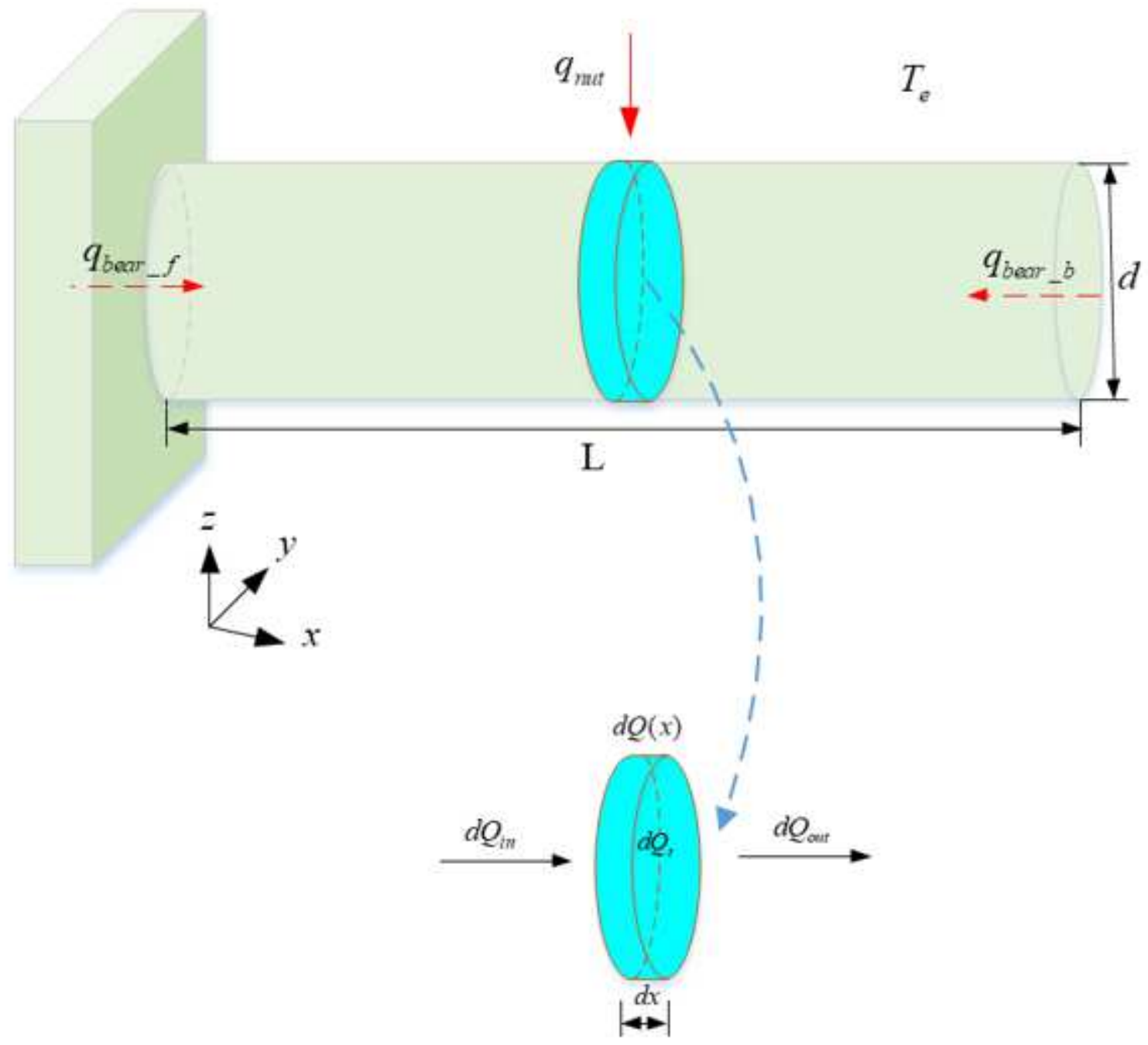

Figure 3

Thermal analysis of screw micro unit

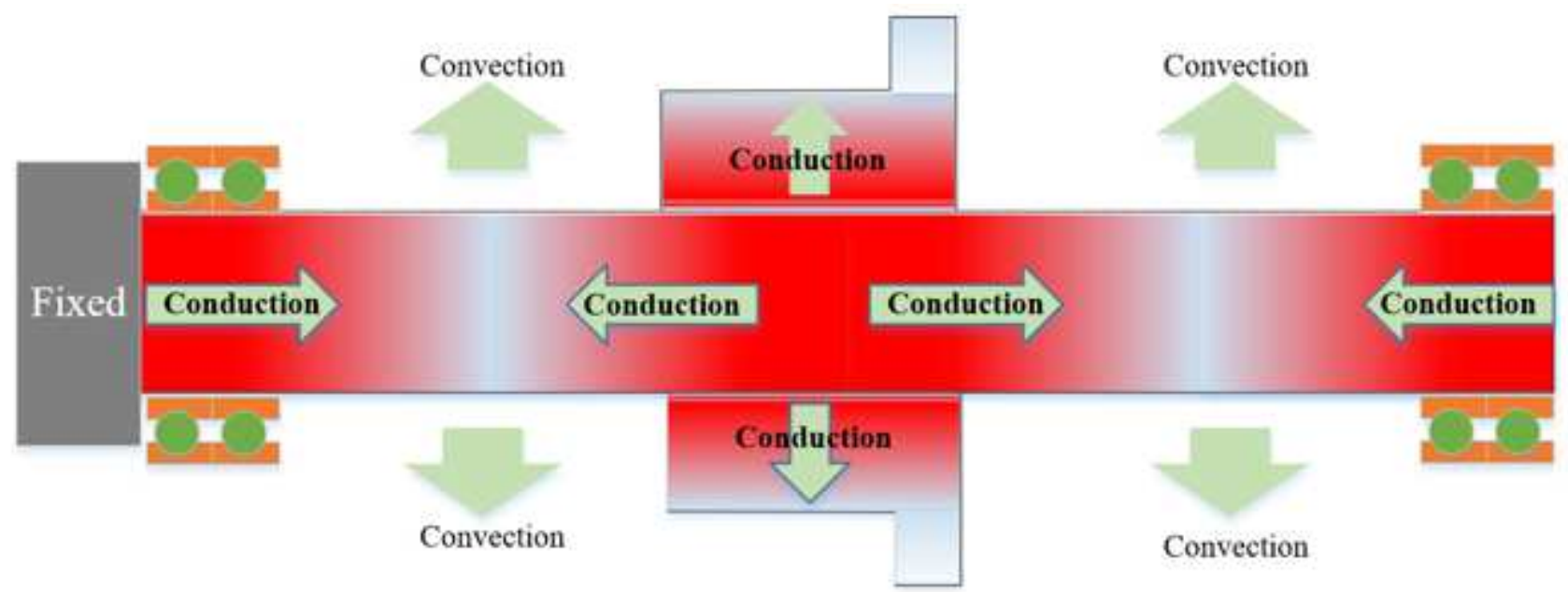

Figure 4 
Two-dimensional heat transfer and temperature distribution of screw-nut feed system

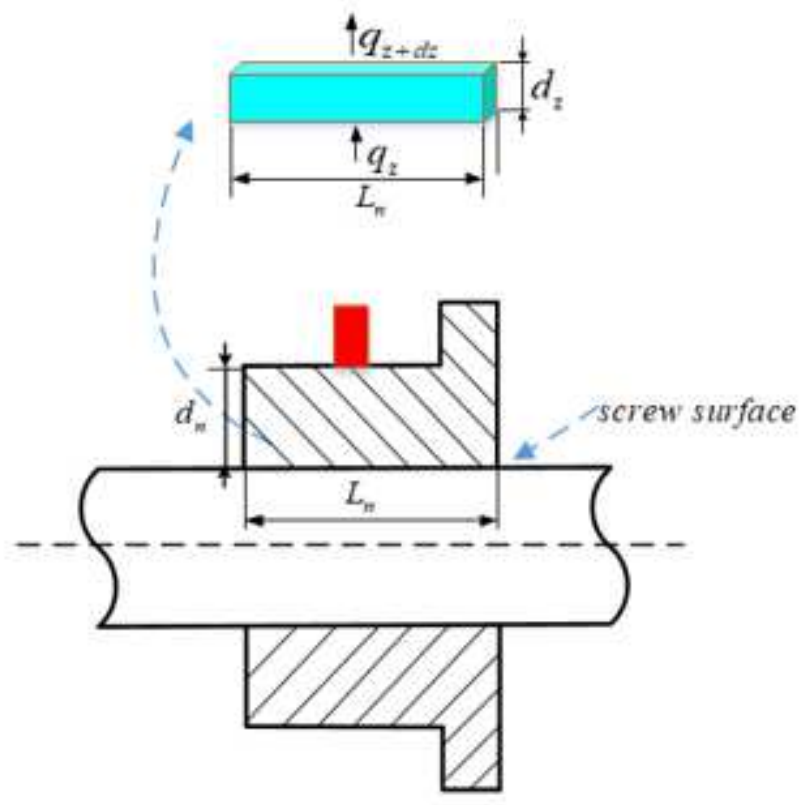

A-A
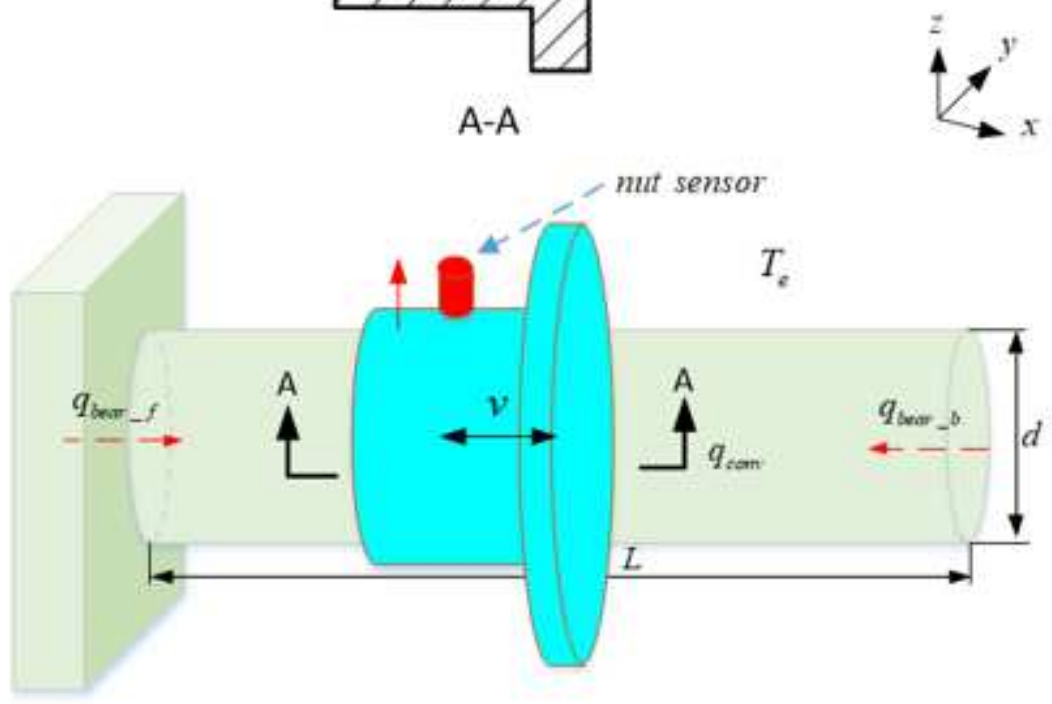

Figure 5

Thermal analysis of nut element

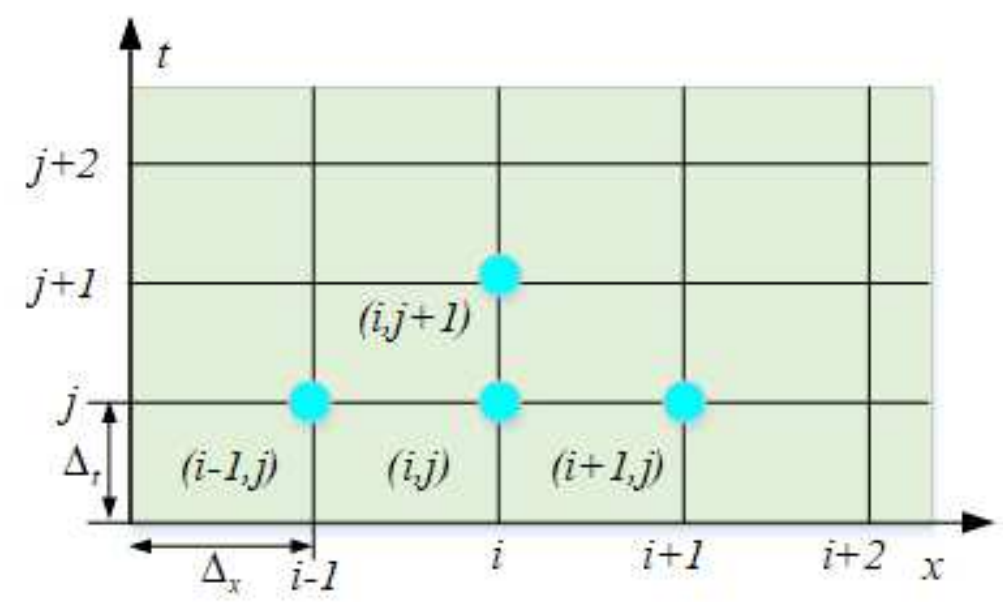


Figure 6

The scheme differential mesh

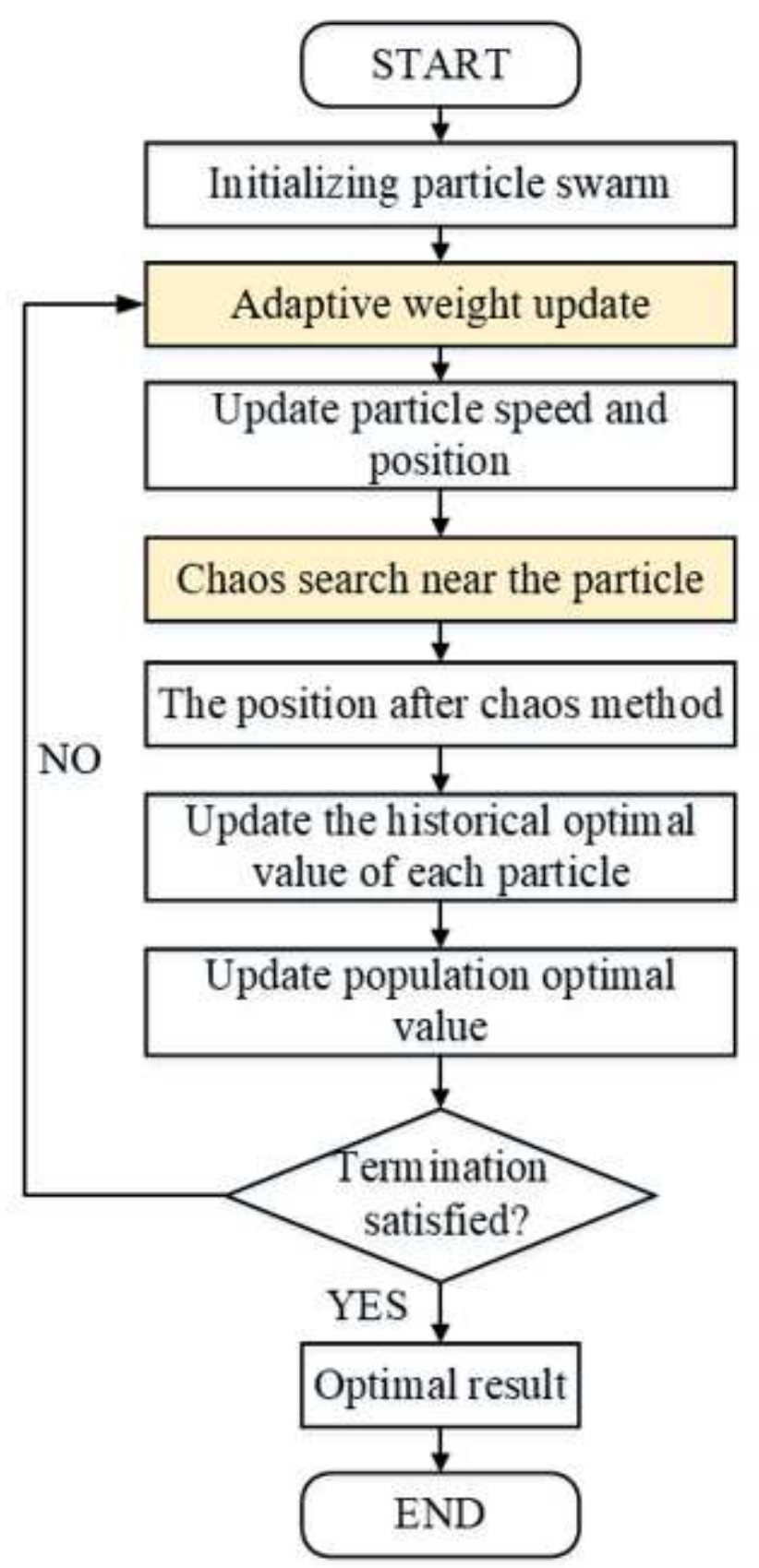

Figure 7

Process of IPSOA 


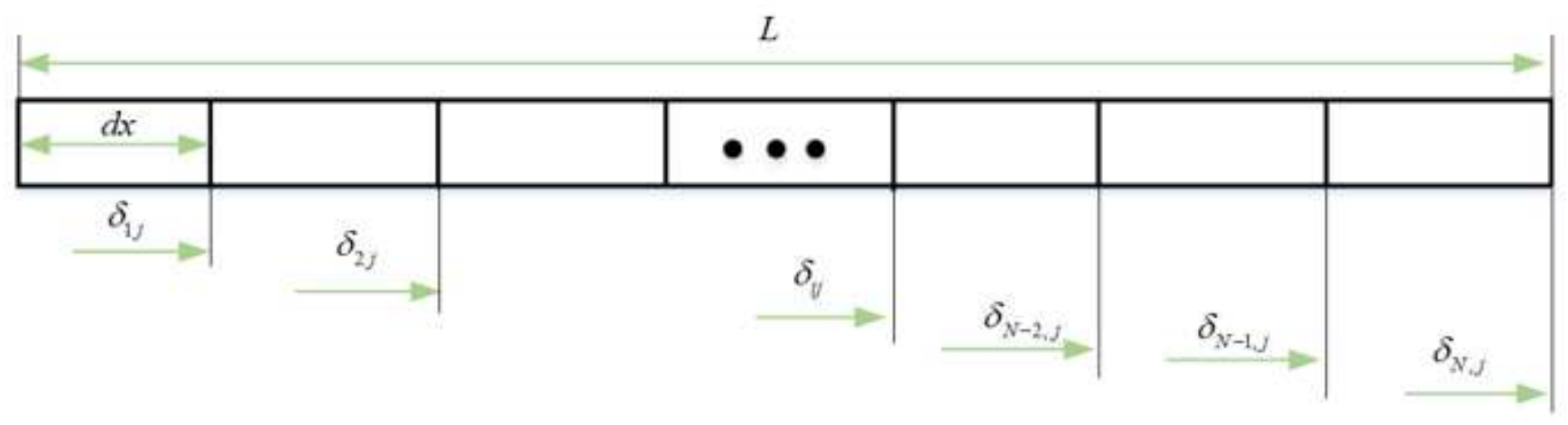

Figure 8

Screw deformation diagram of time $\mathrm{j}$

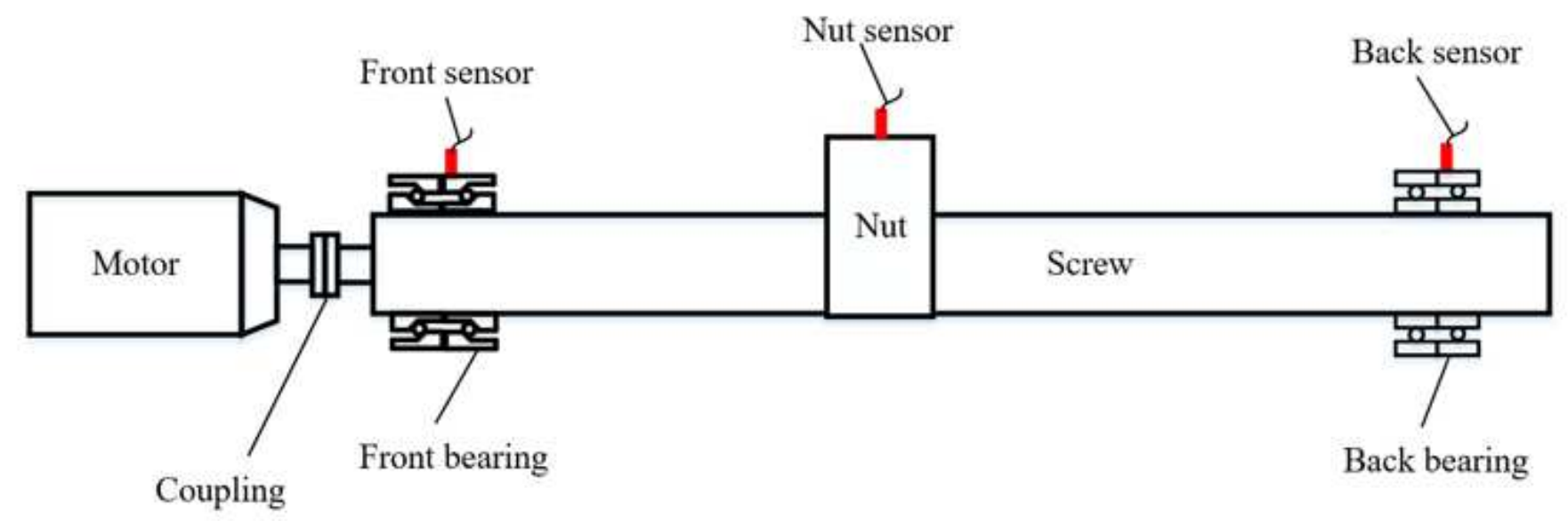

Figure 9

Mounting position of temperature sensors 


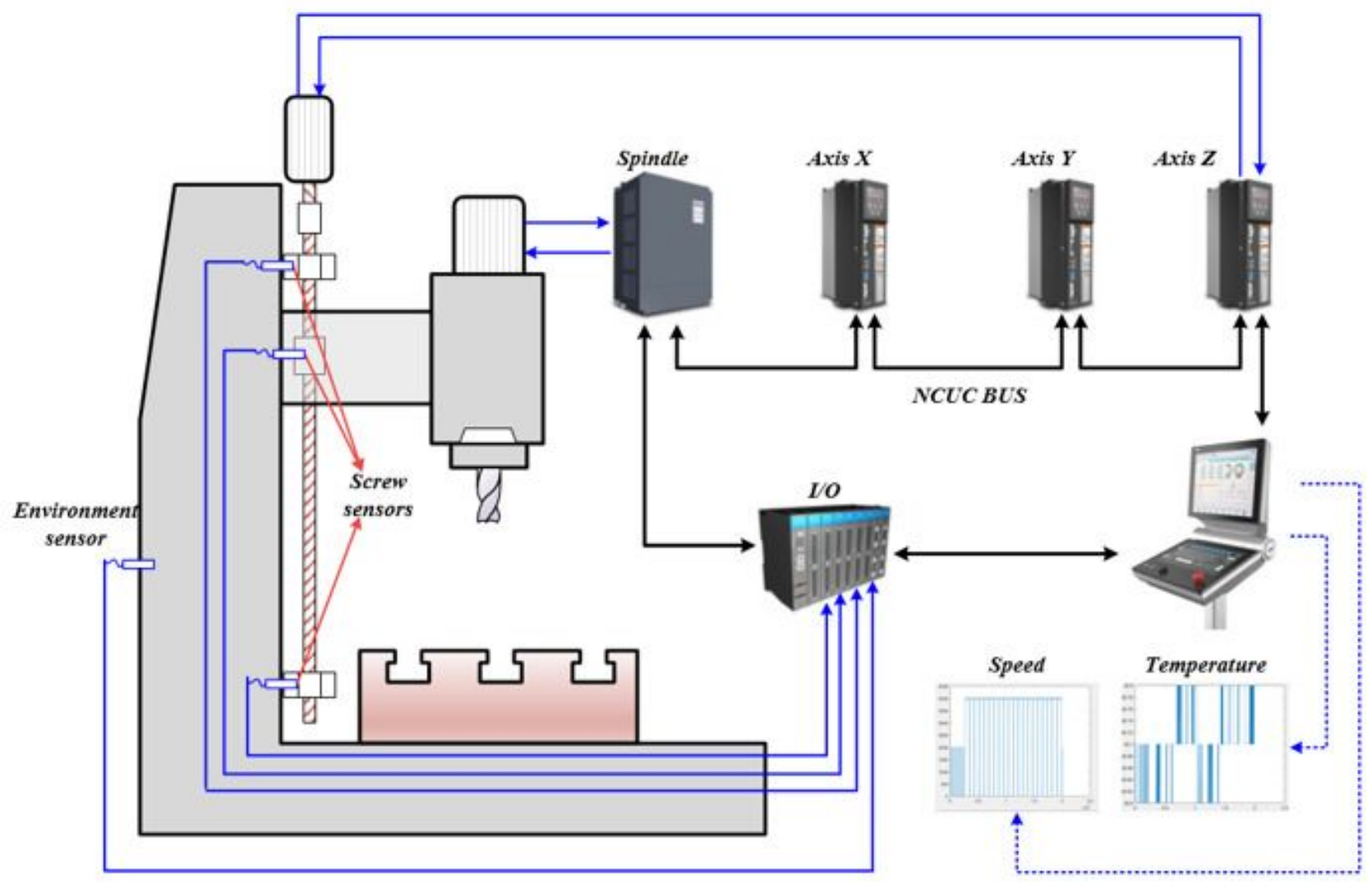

(a) Data acquisition of numerical control system

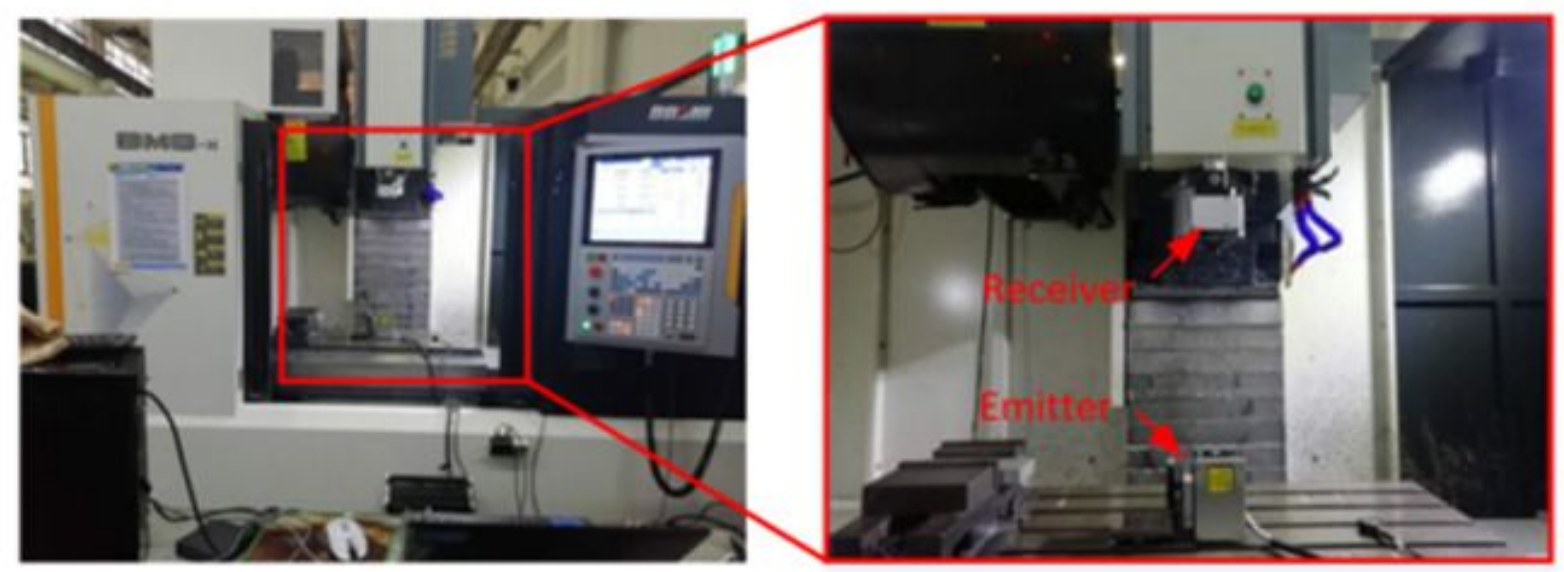

(b)Installation method of XM60 laser interferometer

Figure 10

Data acquisition of thermal error 


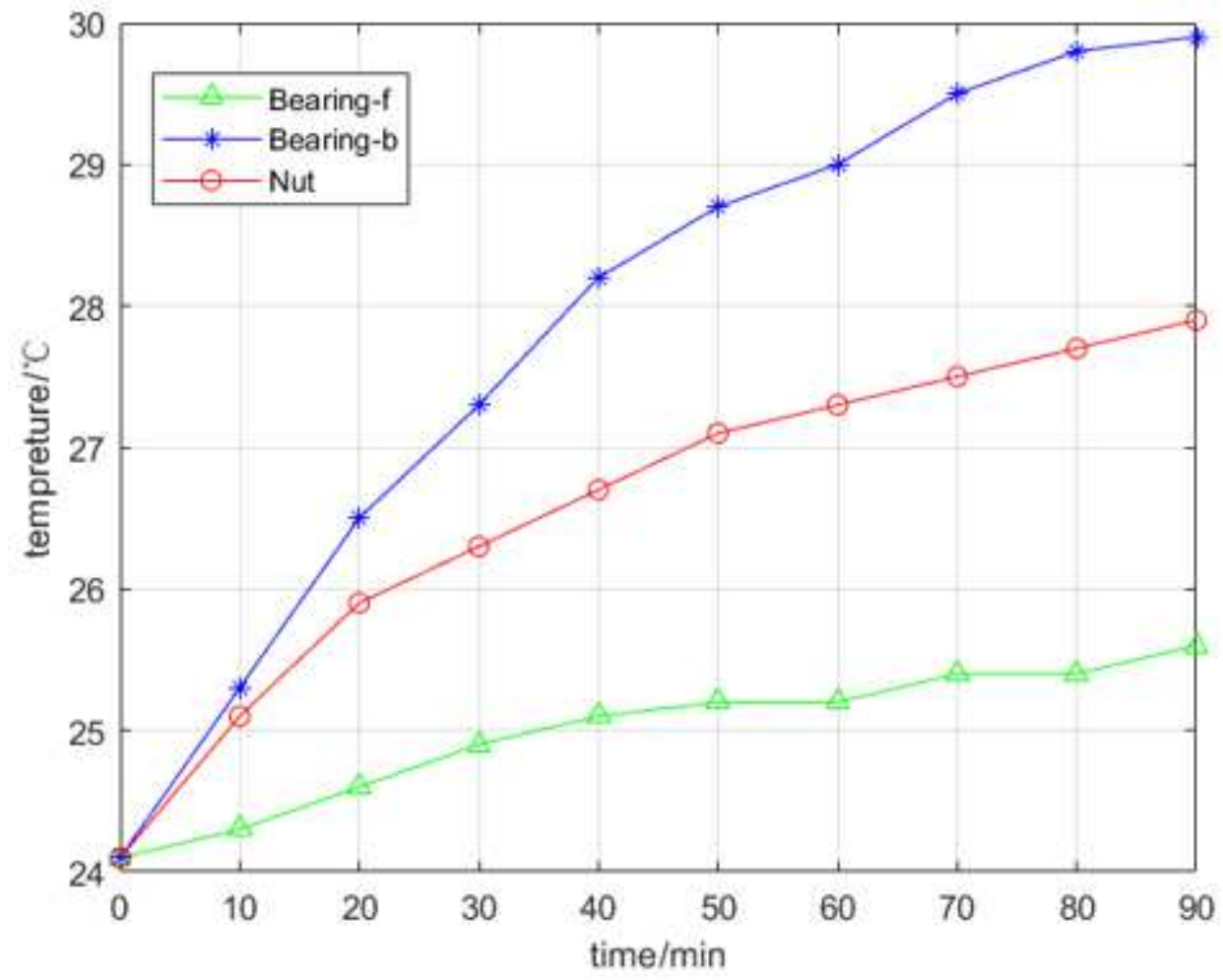

Figure 11

Temperature diagram of screw measuring point

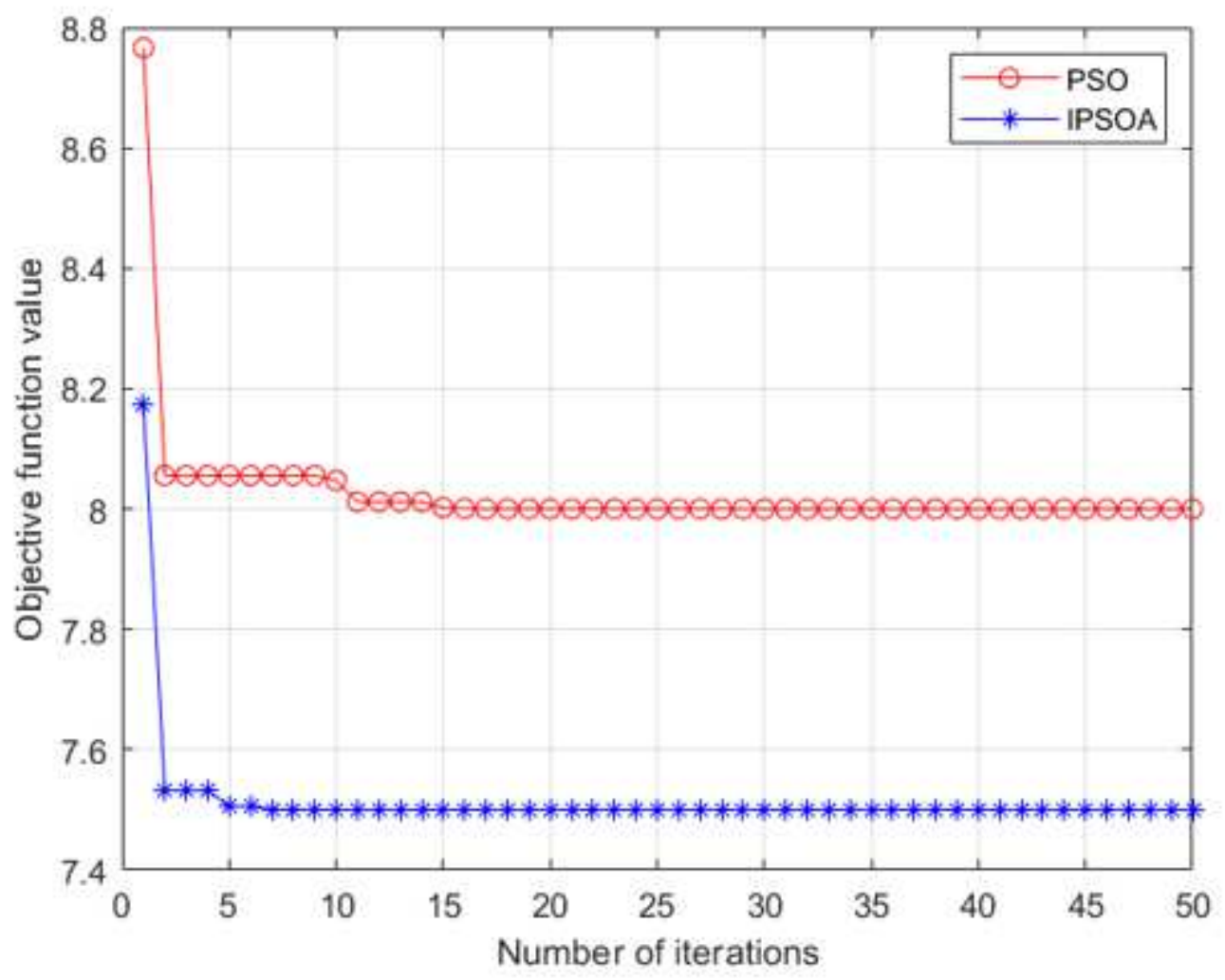

Figure 12 
Temperature diagram of screw measuring point

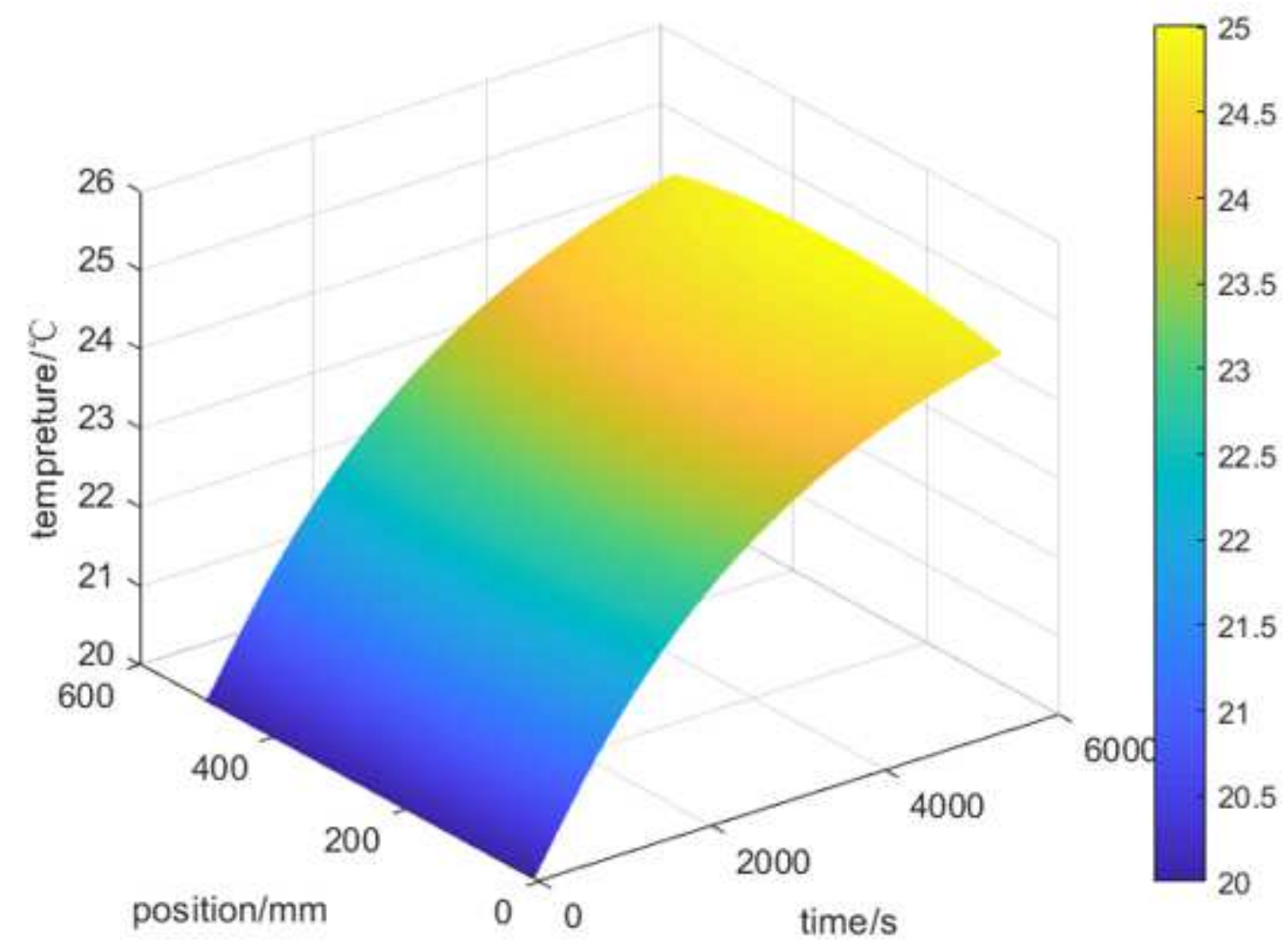

Figure 13

Temperature under different position and time 


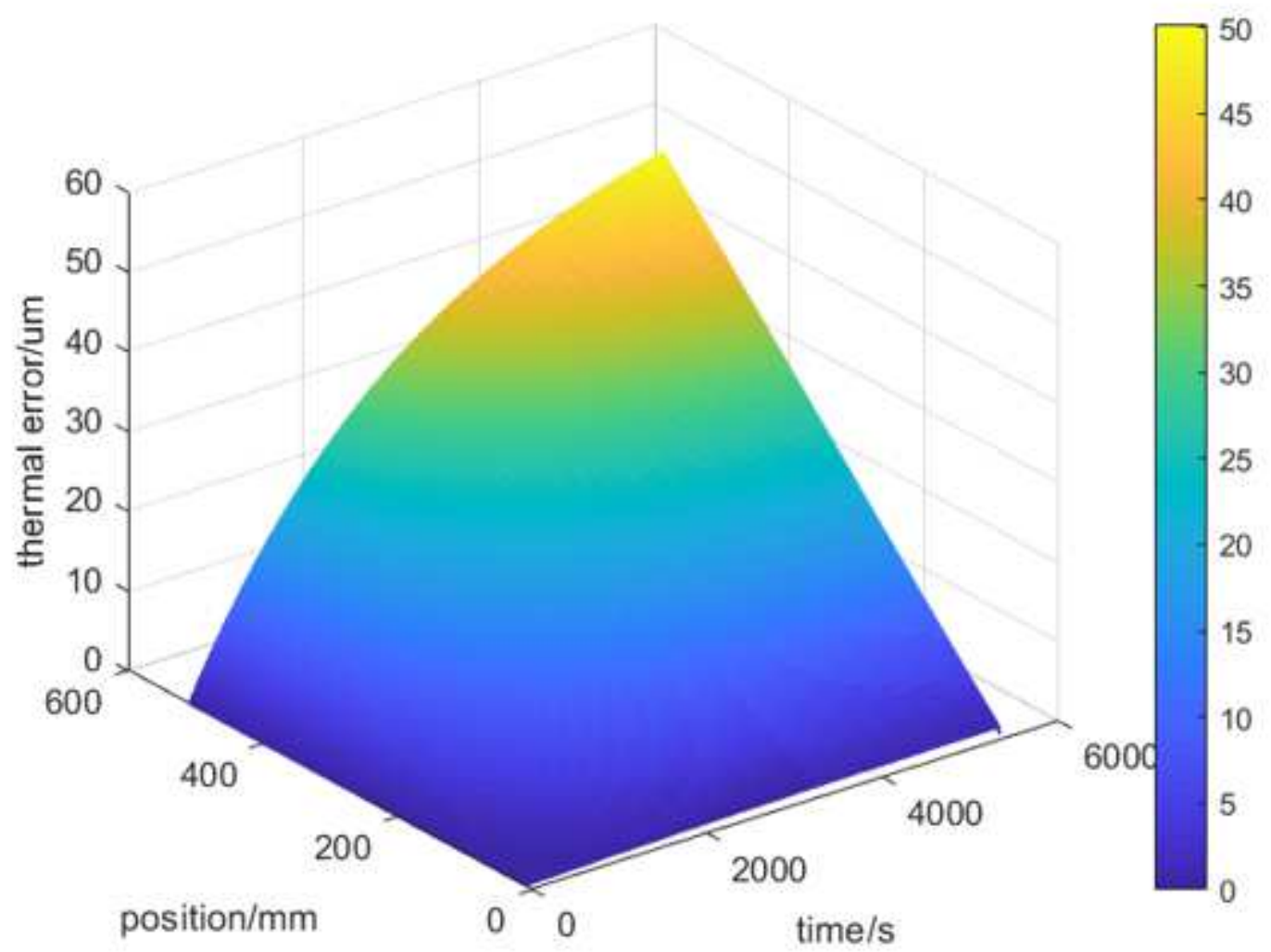

Figure 14

Thermal error under different position and time
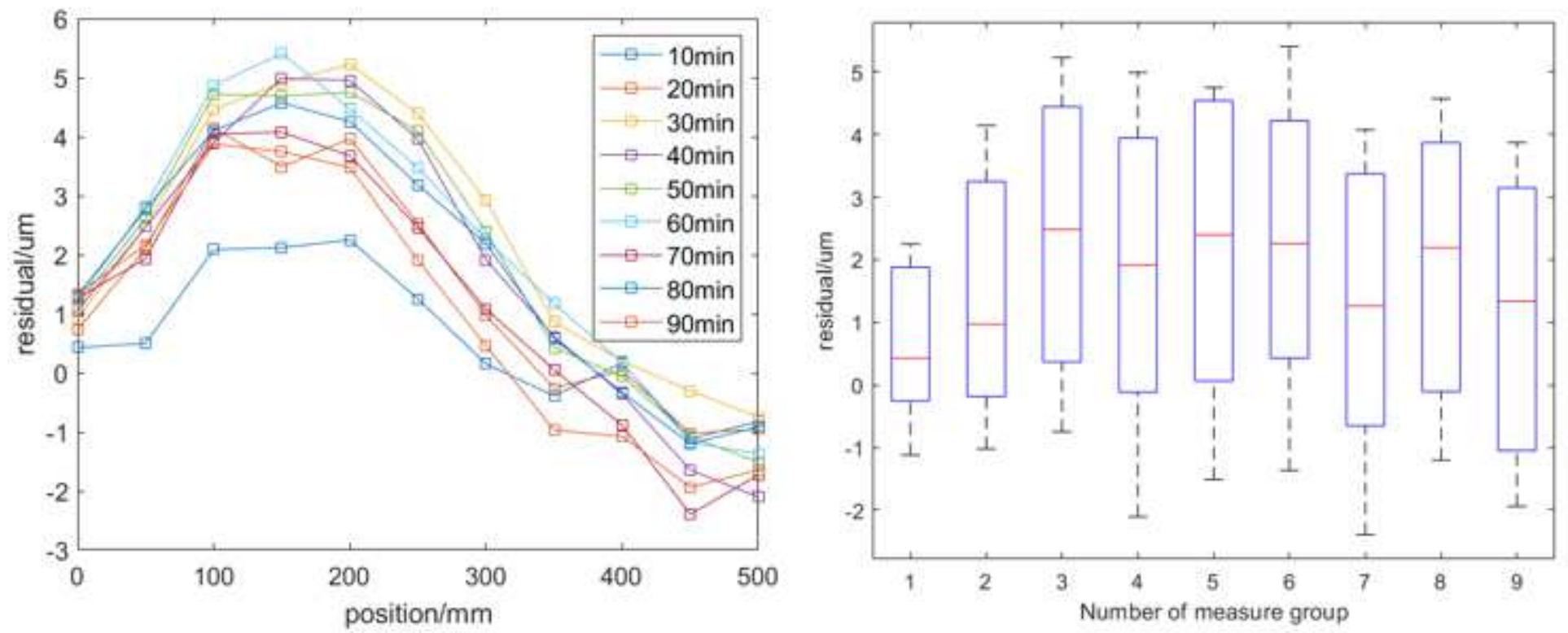

Figure 15

Residual of predict experiment 1\# 

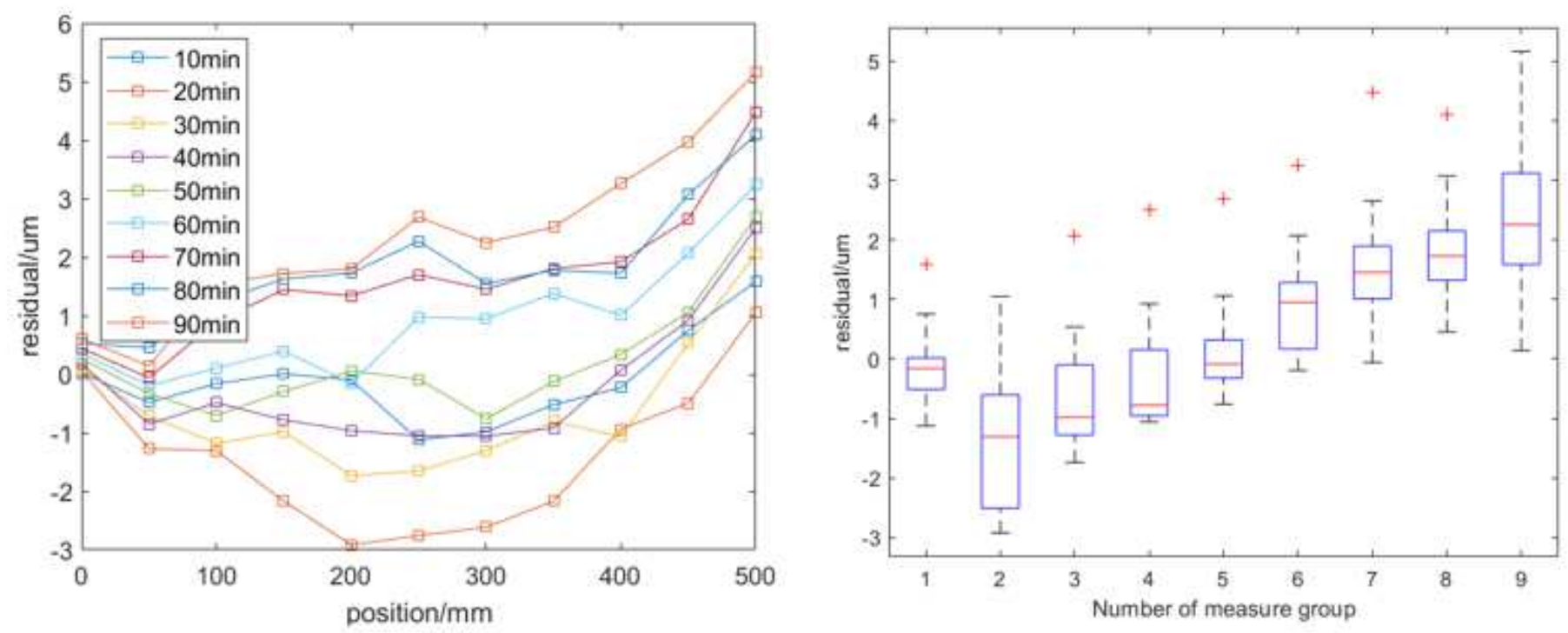

Figure 16

Residual of predict experiment 2\#
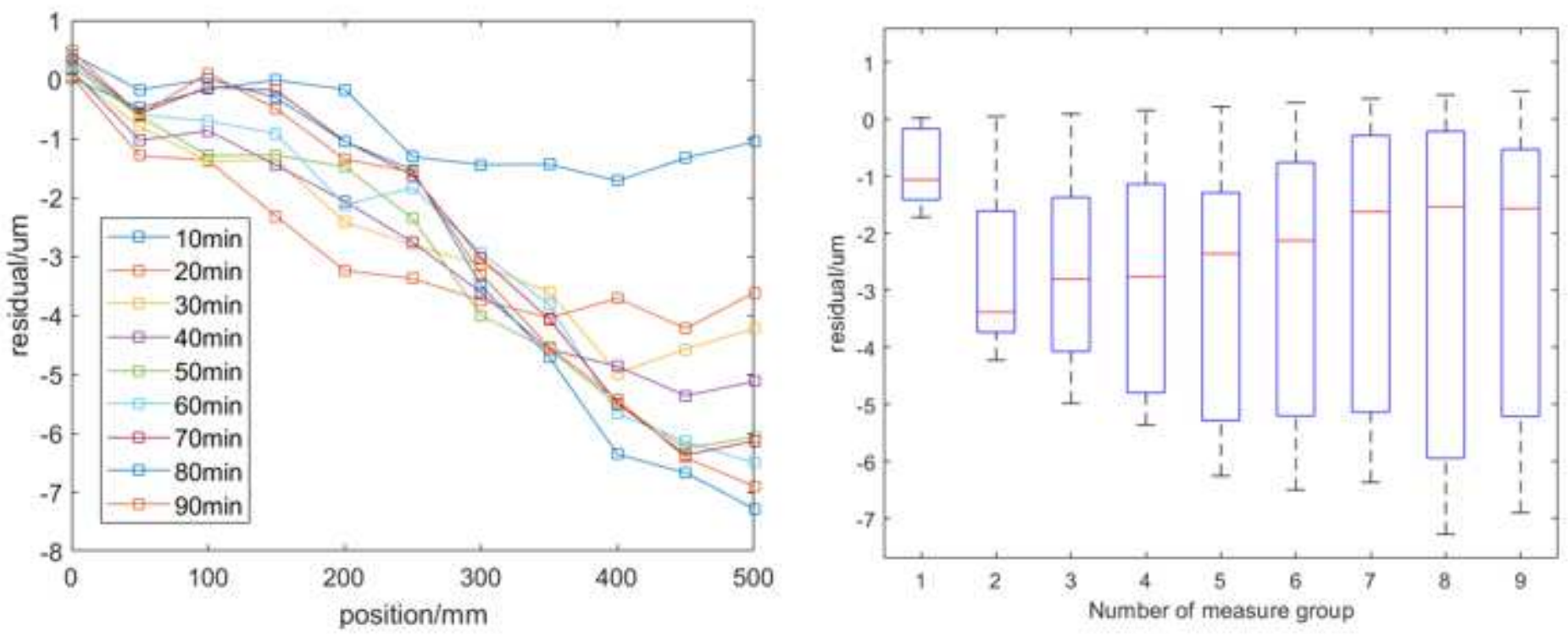

Figure 17

Residual of predict experiment 3\# 